NBER WORKING PAPER SERIES

\title{
EMPLOYED IN A SNAP? THE IMPACT OF WORK REQUIREMENTS ON PROGRAM PARTICIPATION AND LABOR SUPPLY
}

\author{
Colin Gray \\ Adam Leive \\ Elena Prager \\ Kelsey B. Pukelis \\ Mary Zaki \\ Working Paper 28877 \\ http://www.nber.org/papers/w28877
NATIONAL BUREAU OF ECONOMIC RESEARCH
1050 Massachusetts Avenue
Cambridge, MA 02138
June 2021

We thank David Autor, Marianne Bitler, Sebastian Calonico, Itzik Fadlon, Amy Finkelstein, Jon Gruber, Tatiana Homonoff, Ben Hyman, Brian Kovak, Tim Layton, Katherine Meckel, Robert Moffitt, Matt Notowidigdo, John Pepper, Chris Ruhm, Sebastian Tello-Trillo, and seminar participants at Columbia, MIT, UVA, the Census Bureau, ASHEcon 2018, and the Chicago Health Economics Workshop for helpful comments and suggestions. We are grateful to Jeff Price at Virginia Department of Social Services (DSS) for his support and assistance throughout the project. We also thank Nikole Cox, Claudia Jackson, Bill McMakin, and others in Virginia DSS who helped us understand institutional details and provided additional data assistance. Leive's work on this project was supported in part by grant 1R01MD014970-01 from the National Institute on Minority Health and Health Disparities. Gray's work on this project was supported in part by the National Science Foundation Graduate Research Fellowship Program under Grant No. 1122374. This research does not necessarily reflect the views of any of the funders. This research does not necessarily reflect the views or opinions of Wayfair or the National Bureau of Economic Research.

NBER working papers are circulated for discussion and comment purposes. They have not been peer-reviewed or been subject to the review by the NBER Board of Directors that accompanies official NBER publications.

(C) 2021 by Colin Gray, Adam Leive, Elena Prager, Kelsey B. Pukelis, and Mary Zaki. All rights reserved. Short sections of text, not to exceed two paragraphs, may be quoted without explicit permission provided that full credit, including $\odot$ notice, is given to the source. 
Employed in a SNAP? The Impact of Work Requirements on Program Participation and Labor Supply

Colin Gray, Adam Leive, Elena Prager, Kelsey B. Pukelis, and Mary Zaki

NBER Working Paper No. 28877

June 2021

JEL No. H53,I30,I38,J22

\section{ABSTRACT}

Work requirements are common in U.S. safety net programs. Evidence remains limited, however, on the extent to which work requirements increase economic self-sufficiency or screen out vulnerable individuals. Using linked administrative data on food stamps (SNAP) and earnings with a regression discontinuity design, we find robust evidence that work requirements increase program exits by 23 percentage points (64 percent) among incumbent participants after 18 months. There is a 53 percent overall reduction in program participation among adults who are subject to work requirements. Homeless adults are disproportionately screened out. We find no effects on employment, and suggestive evidence of increased earnings in some specifications. Our findings indicate that, per dollar of public expenditure, eliminating work requirements would likely transfer more resources to low-income adults than other programs targeting the same population.

Colin Gray

Wayfair

4 Copley Place

Boston, MA 02116

cgray3@wayfair.com

Adam Leive

Batten School of Leadership and Public Policy

University of Virginia

109 Garrett Hall, 235 McCormick Road

Charlottesville, VA 22904

leive@ virginia.edu

Elena Prager

Kellogg School of Management

Northwestern University

2211 Campus Drive

Global Hub 4269

Evanston, IL 60208

and NBER

elena.prager@kellogg.northwestern.edu
Kelsey B. Pukelis

Harvard University

Cambridge, MA

kelseypukelis@g.harvard.edu

Mary Zaki

University of Maryland

2200 Symons Hall

College Park, MD 20742

mzaki@umd.edu 


\section{Introduction}

Policymakers seek to provide benefits to low-resource households in times of need without reducing employment incentives. One common strategy is to require adults who are capable of working to sustain formal employment or participate in community service in order to receive benefits. Since 1996, some form of "work requirement" has existed in many means-tested programs, including Temporary Assistance for Needy Families (TANF) and the Supplemental Nutrition Assistance Program (SNAP). Proponents argue that work requirements improve labor force attachment and, in the long run, promote self-sufficiency. Opponents contend that the primary effect of work requirements is to reduce benefits for the most vulnerable recipients in times of need (Hahn and Haskins 2018, Fadulu 2019).

Work requirements are once again taking center stage in policy debates: SNAP enrollment has risen sharply since the start of the Covid-19 pandemic, and while all states initially suspended work requirements due to the crisis, many are debating reintroducing the policy. For example, Florida announced that work requirements would be enforced before suspending them in response to public pressure (Delgado 2020). Congress has debated extending a suspension first passed in March 2020 at the federal level (Peterson 2020). Previously, a proposed expansion of SNAP's work requirements was the central point of contention in the 2018 Farm Bill. In Medicaid, many states attempted to add work requirements before being blocked by federal court decisions in 2019 and $2020{ }^{1}$

This paper evaluates the impact of work requirements on the program participation and labor market outcomes of able-bodied adults without dependents (ABAWDs) in the context of SNAP. We use detailed administrative data from Virginia and a transparent regression discontinuity $(\mathrm{RD})$ identification strategy that exploits the fact that participants sharply age out of work requirements at age 50 .

To date, research on work requirements has struggled with several empirical challenges. First, commonly used survey data sources severely and non-randomly under-report participation in means-tested programs (Meyer et al. 2014, Ziliak 2015, Meyer and Mittag 2019). Second, studying responses among a sample of able-bodied adults without dependents inadvertently includes individuals who would not participate in SNAP under any policy regime. This overly broad sample produces an estimate that is closer to an intent-to-treat than to treatment-on-the-treated, making it difficult to distinguish small effects from low participation. Third, selection bias may arise from attempts to limit the study sample to those most likely to be impacted by work requirements. For example,

\footnotetext{
${ }^{1}$ In Gresham v. Azar, the United States Court of Appeals for the D.C. Circuit ruled against work requirements in Arkansas.
} 
limiting the sample to incomes below a specified poverty threshold excludes individuals who raise their incomes above this threshold in response to work requirements. Some argue that these biases explain the lack of evidence that work requirements cause large improvements in labor market outcomes (Rachidi and Doar 2018).

To overcome these empirical challenges, we leverage unique administrative data spanning nearly a decade to focus on a relevant subset of non-disabled, childless beneficiaries subject to work requirements. We identify a sample of ABAWDs who likely would be on SNAP absent work requirements. From 2009 to 2013, Virginia experienced a prolonged period without SNAP work requirements, which were suspended during the Great Recession and reinstated in October 2013. We identify all ABAWDs who were enrolled in SNAP at the end of this multi-year period without work requirements and then follow them forward after work requirements are reinstated. By defining the sample during a time before work requirements, this "stock" population captures our ABAWD population of interest, yielding reliable estimates that both minimize selection bias and capture the treatment-on-the-treated.

We find strong evidence that work requirements dramatically reduce SNAP participation among ABAWDs. Virginia's introduction of work requirements reduced overall participation among ABAWDs (including individuals outside our "stock" population) near the age cutoff by 53 percent eighteen months after work requirements were reinstated. This decline is twice the size estimated in other studies. Time patterns of participation, RD estimates, and placebo checks all corroborate this conclusion. Moreover, we provide suggestive evidence that the estimated magnitude of the participation reduction is generalizable to ages further from the policy cutoff. In RD analyses focusing only on the stock population, we find that the introduction of work requirements reduced the rate of eighteen-month program retention by 37.0 percent (23.4 percentage points) among existing SNAP participants from a baseline of 0.632 to 0.398 . Equivalently, work requirements increased exits by 63.6 percent (23.4 percentage points) from a baseline of 0.368 to 0.602.

Our longitudinal data also allow us to study screening using ex ante observed covariates by classifying individuals on the basis of characteristics measured up to eight years prior to treatment. This avoids the bias that would arise from conditioning on characteristics that may themselves be endogenous to the policy, such as contemporaneous employment. We find that work requirements induce disproportionately higher exit among beneficiaries who are documented to be homeless or to have no earned income prior to the reinstatement of work requirements. In contrast, induced exit is disproportionately lower among those with a history of disability, who are more likely to be exempt from the work requirements.

Unlike the large effects on program participation, effects on employment are limited. 
Our point estimates are close to zero and we statistically rule out average employment increases above 3.5 percentage points. There is evidence of increased earnings near a key eligibility threshold, however, based on unconditional quantile regressions. To evaluate the costs and benefits of the policy, we calculate the marginal value of public funds (MVPF) by comparing the value to participants of eliminating work requirements against the costs to the government. The MVPF implies that eliminating work requirements would likely transfer more resources to SNAP participants per dollar of public expenditure than other programs targeting similar populations.

The paper builds upon a body of research studying work requirements and screening in means-tested programs. It is closely related to the theory developed by Besley and Coate (1992), which formalizes the trade-off between providing safety net benefits and avoiding work disincentives. The corresponding empirical literature documents the work disincentives inherent in means-tested and social insurance programs, providing evidence that income effects explain much of the causal relationship between government assistance and work (Autor and Duggan 2007, Fetter and Lockwood 2018). A handful of papers explore this relationship specifically in the setting of food stamps (Fraker and Moffitt 1988, Keane and Moffitt 1998, Hagstrom 1996, Hoynes and Schanzenbach 2012).

A complementary empirical literature studies whether work requirements can help to circumvent the trade-off in Besley and Coate (1992) by promoting work. In the context of traditional welfare programs, a number of studies find that work requirements increase employment and program exit, but decrease total income as many households exit without employment (Fang and Keane 2004, Grogger and Karoly 2005, Greenberg et al. 2009, Chan 2013, Card and Hyslop 2005, Chan and Moffitt 2018). A number of papers investigate this question in the context of SNAP. They find mixed results, likely due to differences in methods, data, and the potential presence of selection biases and non-treated populations as discussed above. Among these are several papers that use the age 50 eligibility cutoff for identification (Stacy et al. 2018, Harris 2021, Han 2020, Cuffey et al. 2015, Ritter 2018). These studies primarily rely on cross-sectional survey data, and find mixed results for participation and labor market outcomes. In a study using administrative SNAP data, Ribar et al. (2010) find moderate impacts on participation but do not estimate causal effects on labor market outcomes. Research describing how aggregate SNAP participation moves with macroeconomic conditions finds that large reductions in participation coincide with work requirements (Wilde et al. 2000, Ziliak et al. 2003, Ganong and Liebman 2018). We review these closely related papers in detail in Section 2.2.

Our results also contribute to the literature on screening in means-tested programs, which Nichols and Zeckhauser (1982) and Besley and Coate (1992) highlight as a policy tool 
to increase targeting efficiency. A recent literature empirically studies the role of screening by enrollment and recertification processes in Medicaid, SNAP, and disability programs (Deshpande and Li 2019, Finkelstein and Notowidigdo 2019, Gray 2019, Homonoff and Somerville 2019). Our finding of disproportionate program exit among the homeless and individuals without pre-SNAP income provides new insights on the screening effects of work requirements, in particular.

This paper proceeds as follows. Section 2 discusses work requirements in SNAP, the policy variation available, and the administrative data we use. Section 3 documents participation survival curves and trends over time, and presents our main regression discontinuity estimates of total participation reductions. Section 4 uses our stock population definition to estimate the effect of work requirements on program retention, assess screening impacts, and study the role of additional verification requirements. Section 5 presents regression discontinuity evidence regarding labor market outcomes, including analyses of heterogeneous impacts along the earnings distribution and a discussion of the implications for the marginal value of public funds. Section 6 concludes.

\section{Setting and Data}

\subsection{SNAP Work Requirements and Policy Variation}

The Supplemental Nutrition Assistance Program (SNAP), previously called the Food Stamp Program, is among the largest poverty alleviation programs in the United States. In 2015, the program provided over $\$ 69$ billion in benefits to over 45 million individuals, representing 14 percent of the U.S. population (Ganong and Liebman 2018). SNAP is administered at the state level, but the core aspects of the program are the same nationwide, regulated by the United States Department of Agriculture (USDA).

Each month, SNAP households get money loaded onto an Electronic Benefits Transfer (EBT) card, which they can use to buy most food and beverages at authorized grocery or convenience stores. With some exceptions, households are deemed ineligible for benefits if their gross income (before deductions) exceeds 130 percent of the Federal Poverty Line (FPL) or if their net income (after deductions) exceeds 100 percent of the FPL. Some states also use a household asset test. The federal government annually sets a maximum monthly benefit amount that increases with household size. Households with positive net income, defined as gross income less permitted deductions (e.g., medical expenses, dependent care), receive 30 fewer cents in benefits for each dollar of net income. ${ }^{2}$

\footnotetext{
${ }^{2}$ There is a 20 percent earned income deduction. This implies that SNAP benefits effectively decline by
} 
To keep track of income and deductions, participants in most states are required to submit periodic "recertifications," typically at 6-month or 12-month intervals. Recertifications require substantial paperwork, including documentation of deductions and earnings (e.g., medical bills or pay stubs), and the majority of attrition from the SNAP program happens at these deadlines (Hastings and Shapiro 2018, Gray 2019, Homonoff and Somerville 2019).

SNAP imposes two distinct types of work requirements. This paper studies the "ABAWD" or "time limit" work requirement, which is the more demanding of the two. The requirement applies only to able-bodied adults without dependents (ABAWDs): adults aged 18-49 who do not report a child in the household and do not meet a limited set of exemptions (e.g., a confirmed disability; see USDA Food and Nutrition Service (2019)). These individuals are required to work, participate in qualifying job training programs, or do approved community service for at least 80 hours each month. ABAWDs who do not meet these requirements may receive benefits for a maximum of three months within a three-year period. The second type of work requirement is both more general and weaker. It requires participants aged 16-59 to consent to work registration, not quit current employment, and accept employment or participate in training programs only if offered. Throughout the paper, we focus exclusively on the more stringent ABAWD work requirements and use the phrase "work requirements" to refer to them.

To illustrate how work requirements may affect program participation and labor supply, Appendix Figure A.1 presents a stylized budget constraint for ABAWDs. Work requirements produce a notch in the budget constraint at the minimum hours threshold. Some SNAP participants would choose to increase labor supply to retain benefits compared to their preferred choice without work requirements. This response represents the "incentive effect" of the policy. On the other hand, SNAP participants working few hours in the absence of work requirements might find it too costly to reach the hours threshold and therefore exit the program. Some may work more than they previously did to make up for the lost SNAP benefits. This response represents an "income effect."

Our main identification strategy uses a regression discontinuity (RD) design to take advantage of the sharp change in ABAWDs' exposure to work requirements at age 50. There are no other rules within SNAP, TANF, or Medicaid that change discontinuously at age 50 that can confound this identification strategy, and childless adults were not eligible for TANF or Medicaid in Virginia during our sample period. Eligibility requirements for Supplemental Security Income (SSI) and Social Security Disability Income (SSDI) do loosen at age 50 due to the occupational grids used to determine disability status (Chen and van der Klaauw

24 cents for each additional dollar of earned income. 
2008, Deshpande et al. 2019). We therefore check for (and find no evidence of) confounding effects at the age 50 discontinuity in "placebo" time periods when work requirements were not in effect.

In addition to the discontinuity at age 50, we take advantage of three other sources of variation in ABAWDs' exposure to work requirements. First, the American Recovery and Reinvestment Act (ARRA) of 2009 exempted all counties in all states from ABAWD work requirements as part of the Great Recession stimulus package. ${ }^{3}$ Individual states began to reinstate work requirements over the subsequent few years. Virginia reinstated ABAWD work requirements statewide on October 1, 2013. The ARRA time period allows us to construct our "stock" sample consisting of participants who entered SNAP in the absence of work requirements. Second, counties with a sufficiently high unemployment rate can waive ABAWD work requirements (see Appendix A). Starting in May 2014, 23 of Virginia's 133 counties were granted county-wide exemptions from work requirements on this basis. ${ }^{4}$ Our main analyses focus on the 110 counties in which work requirements remained in place after October 2013. Data from the 23 counties reinstating exemptions are used in supporting analyses.

Third, Virginia gradually rolled out the reinstatement of work requirements to incumbent SNAP participants. Prior to the reinstatement of work requirements, ABAWDs were generally assigned 12-month recertification periods. After reinstatement, newly enrolling ABAWDs were assigned 6-month or, later, 4-month recertification periods. ${ }^{5}$ Importantly, incumbent ABAWDs who were enrolled in SNAP prior to the reinstatement of work requirements were not assigned these shortened recertification periods until the expiration of their ongoing 12-month recertification. Removal from the SNAP program due to non-compliance with work requirements did not occur until the end of these shortened recertification periods. The gradual roll-out of the shortened recertification periods informs our choice of sample period. In order to accurately capture the impact of work requirements while accounting for this gradual roll-out, our main RD estimates focus on participation and employment on March 2015, 18 months after the reinstatement of work requirements. This is the first month that the shortened recertification periods expire for

\footnotetext{
${ }^{3} \mathrm{~A}$ few states and localities, including Texas and New York City, kept work requirements in place despite the exemption option provided by ARRA (Center on Budget and Policy Priorities 2019). Virginia used the ARRA exemptions as written by USDA.

${ }^{4}$ In addition to Virginia's 95 counties, the state classifies 38 independent cities as county-equivalents for Census purposes. We refer to both "true" counties and these 38 cities as counties. See Appendix A for a list of re-exempted counties.

${ }^{5}$ The 6 months were composed of the 3 allowed months of benefits without meeting work requirements within a 36-month window, an initial partial month of benefits that does not count towards the 3 allowed months, and 2 months of exemptions allotted by the USDA (see USDA Food \& Nutrition Service 2015 and Appendix A for more details).
} 
all incumbent participants enrolled prior to the time of reinstatement. ${ }^{6}$ We provide estimates for a range of other time periods in secondary analyses.

\subsection{Related Literature}

As discussed in the introduction, this paper is most closely related to other papers studying the effects of work requirements in SNAP, although our empirical approach departs from this literature. This section reviews both published work and contemporaneous working papers. While a number of papers have studied SNAP work requirements, including some using the age 50 cutoff, their reliance on survey and cross-sectional data raises specific identification concerns.

First, several studies using aggregated state- or county-level SNAP caseloads document that the implementation of work requirements coincides with substantial reductions in program participation (Wilde et al. 2000, Ziliak et al. 2003, Ganong and Liebman 2018). These studies typically use variation over time and geography in work requirements policies. For example, Ganong and Liebman (2018) find that work requirement waivers can explain 10 percent of increases in SNAP participation during and after the Great Recession. In contrast, Danielson and Klerman (2006) use an index that measures state-level severity of ABAWD time-limits based on state-specific implementations of work requirements and find no significant difference between the index and Food Stamp participation. These studies are somewhat limited by the aggregate nature of their data and the potential for legislative endogeneity.

Second, Ribar et al. (2010) use household-level administrative data from South Carolina between 1996 and 2005 and variation in work requirements across counties and over time. They find participation reductions of up to 20 percent, which are less than half the magnitude that we estimate. This discrepancy may arise from their pre-Great Recession sample period, from heterogeneity in impacts across states, or from the use of a sample selected to exclude those who would enroll in SNAP (only) in the absence of work requirements. In addition, Ribar et al. (2010) do not examine employment or earnings as a separate outcome, but instead analyze the rate of exits from SNAP among those with (UI-covered) employment. As we describe in Section 5.2, however, the interpretation of such regressions is not straightforward

\footnotetext{
${ }^{6}$ For example, an ABAWD who entered the program in September 2013 (immediately before work requirements are reinstated) might not make contact with the SNAP office again until September 2014, when she would be notified of upcoming recertification requirements and removed from the program in March 2015 if they were not met. Virginia stopped the practice of using USDA-allotted exemptions to extend recertification periods in October 2014, possibly shrinking assigned recertification periods for incumbent ABAWDs. As a result, some ABAWDs whose ongoing 12-month recertification periods expired in the fall of 2014 may not have received a full 6 months before their subsequent recertification.
} 
because the empirical design conditions on an outcome, thereby inducing changes in sample composition that frustrates causal estimates (Angrist and Pischke 2009).

Finally, a set of papers closely related to our work use microdata and the age 50 cutoff as a source of identification (Stacy et al. 2018, Harris 2021, Han 2020, Cuffey et al. 2015, Ritter 2018). We summarize the main differences here, and provide further details of findings, strengths, and limitations of these studies in Appendix B. These studies almost exclusively rely on cross-sectional survey data from either the American Community Survey (ACS) or the Current Population Survey (CPS) to measure labor market outcomes. Labor market participation in survey-based populations exceeds that in administrative records. For example, employment rates exceed 70 percent in the control samples of Harris (2021) and Han (2020), which are three to four times higher than in QC data. By contrast, only 17 percent of the Virginia ABAWD SNAP population (and 19 percent of our stock population) is in UI-covered employment when work requirements are reinstated. This is comparable to the 17 percent employed fraction of the nationwide SNAP ABAWD population, as reported in the 2013 QC data. Subsequently, 29 percent of our stock population near age 50 is employed 18 months after reinstatement, which is appreciably smaller than in other study control groups.

Ritter (2018) additionally uses a sample of administrative records of SNAP participants from public Quality Control (QC) Records, which provides a useful cross-section but cannot be used to create a "stock" population for analysis. Samples in these studies are often constructed based on endogenous criteria. ${ }^{7}$ In addition, estimating the effects of work requirements in cross-sectional data is likely to understate the treatment-on-the-treated. This potential underestimation is driven by overly broad sample definitions that include people who would not be on SNAP even absent work requirements. For example, at most 20 percent of those in control samples analyzed in survey-based studies participate in SNAP. By contrast, with longitudinal data, we construct a sample that has 100 percent SNAP participation in month zero.

These existing papers find mixed results for the effects of work requirements on employment and SNAP participation. Using ACS data, Stacy et al. (2018), Harris (2021), and Han (2020) find that work requirements decrease SNAP participation by 10 to 15 percent. While Stacy et al. (2018) find no significant impacts on labor market outcomes, Harris (2021) finds employment increases of 1.5 to 1.8 percent. Han (2020) finds no significant impacts on employment but finds impacts on hours worked. Using CPS data, both Cuffey et al. (2015) and Ritter (2018) find no significant impacts of work

\footnotetext{
${ }^{7}$ This is particularly true for QC-based samples, which suffer from mechanical selection bias as discussed in Ritter (2018).
} 
requirements on labor market outcomes. Cuffey et al. (2015) further find no significant impacts on SNAP participation.

Our ability to link SNAP administrative records with administrative earnings histories provides substantial advantages relative to survey data. The first advantage is improved accuracy: linking UI data to administrative SNAP records allows us to avoid the documented under-reporting of SNAP participation and mismeasurement of income in surveys. Survey data have been shown to undercount SNAP participants by up to 40 percent (Meyer and Mittag 2019, Meyer et al. 2014) and to measure income with systematic errors (Bee and Mitchell 2017). Second, by allowing us to construct our stock population, the linked longitudinal data enable us to more closely approach the treatment-on-the-treated estimate while simultaneously avoiding selection bias. Third, the panel nature of the data makes possible two sets of analyses that are not feasible in repeated cross-sections: We can examine the time path of impacts of work requirements, including whether they induce an increase in self-sufficiency in the medium run. Cross-sectional data will, in contrast, average effects from both new entrants and long-term program participants. We can also study heterogeneous impacts of work requirements by examining heterogeneity across endogenous outcomes measured at baseline. Finally, unlike studies that use public-use versions of surveys, we have more precise information on geography, the timing of observations, and age. These features allow us to more accurately identify who is subject to work requirement waivers or exemptions and to execute a more refined RD strategy with age as the running variable.

\subsection{Administrative Data on SNAP Participation and Earnings}

We use annual administrative records from the Virginia Department of Social Services (DSS) between 2007 and 2015. The files include data on demographics, disability and employment status, housing type, receipt of earned and unearned income, and the first and last calendar months of every SNAP participation spell. Demographics include age in months, gender, education, race, zip code of residence, and county of the participant's SNAP program office. ${ }^{8}$ In addition to age, two additional variables are relevant for determining ABAWD status. The first measures the status of general work registration and reasons for any exemption. The second measures disability status, including which disability programs the SNAP participant is enrolled in.

Our main sample definition uses individuals who have no known exemptions or

\footnotetext{
${ }^{8}$ Not all city-counties have a physical SNAP office located within their borders, but all ordinary counties do. SNAP applicants who apply for SNAP through the wrong program office are still subject to the rules of the county of their residence and their applications are typically either transferred or denied.
} 
disabilities and have no children in their SNAP-defined household. These individuals would typically be considered ABAWDs if they are under age 50, and non-ABAWDs if they are over age 50. To validate this definition in our data, we compare our count of ABAWDs with official counts using external data on ABAWD status and exemptions provided by Virginia DSS. The number of ABAWDs in our data is 96.5 percent of the official count, providing confidence that we are accurately measuring ABAWDs among SNAP participants.

We match the SNAP administrative records to employment records collected for the state's Unemployment Insurance (UI) program. These records contain a panel of quarterly earnings from 2005 to 2017 and have been previously validated against Social Security earnings records (Dean et al. 2017). Using the UI records, we define quarterly employment as an indicator for appearing in the wage data that quarter. Our results are robust to alternative definitions of employment, such as an indicator for earning above the full-time minimum wage. We deflate quarterly earnings to 2018Q1 USD using the all-items CPI.

Despite the advantages outlined in Section 2.2, our data also have some limitations. First, the SNAP administrative data do not report benefit amounts. Second, UI wage records do not capture self-employed workers, federal employees, and independent contractors. This omission may threaten the validity of our estimates if work requirements change the composition of employment. In robustness checks, we find no impact on sources of employment that are self-reported by SNAP participants but not covered by the UI data (Appendix Figure C.9).

A second limitation is that our estimates may not generalize outside of Virginia. For example, some states impose greater reporting burdens and more rigorous verification of work status than Virginia. While we are not equipped to evaluate across-state heterogeneity in how work requirements are implemented, we show in Appendix D.1 that the composition of SNAP recipients in Virginia is similar to nationwide averages based on QC data. In terms of broad economic conditions, Virginia's unemployment rate was in the second-lowest quartile among states during our main sample period (Bureau of Labor Statistics 2016).

Table 1 describes the characteristics of Virginia SNAP participants in September 2013 (the last month before the reinstatement of work requirements), as measured from the Virginia administrative data. We report descriptive statistics separately for adults whom we classify as ABAWDs and adults whom we do not classify as ABAWDs due to either their age, having a dependent, or satisfying a specific exemption. ${ }^{9}$ There are 90,382 unique ABAWDs, which represents roughly 9 percent of the total beneficiary population. The mean age of ABAWDs is 33.0 years, about ten years younger than other adults. A smaller

\footnotetext{
${ }^{9}$ We present descriptive statistics of all SNAP households over the entire period of our data in Appendix C.
} 
share of ABAWDs are female (40 percent of ABAWDs vs. 67 percent of other adults), married (7 percent vs. 21 percent), report unearned income to DSS (7 percent vs. 41 percent), or have ever reported a disability in the past ${ }^{10}$ (10 percent vs. 35 percent). According to UI records, ABAWDs have lower levels of employment and lower annual wage earnings than other adults on SNAP. Finally, ABAWDs are more likely to be homeless (14 percent vs. 2 percent).

While benefit amounts are not included in our data, other sources indicate that SNAP benefits constitute a large and important source of income for this population. We use QC data to tabulate the amount of benefits at stake and how much would be reduced through changes in program participation and labor supply. We restrict the QC data to non-disabled adults aged 18-49 in childless Virginia households who have at least one member of the household who is not excluded from work registration. If work requirements remove participants from SNAP without increasing labor supply, the average household exiting the program would lose $\$ 189$ per month, the maximum for a single-person household during our sample period. This drop constitutes roughly two-thirds of their gross income. If work requirements induce ABAWDs to work more to retain benefits, then SNAP benefits would decline by about $\$ 100$, on average, based on their deductions, hours, and phase-out schedule. We estimate that less than 5 percent of ABAWDs would earn enough by meeting work requirements to become ineligible for SNAP. In short, ABAWDs face the prospect of meaningful reductions in SNAP benefits as a result of the policy.

\section{Effects on Program Participation}

This section estimates the effect of work requirements on total SNAP participation. Section 3.1 documents trends of lower retention and falling total SNAP participation in the wake of work requirements. Section 3.2 then implements RDs to estimate the effect of work requirements on participation. Section 3.2 also shows that slow-downs in the flow of new entrants account for a small minority of the total participation drop. Hence, reduced participation is driven primarily by exit among existing participants and shorter spells among new entrants.

\footnotetext{
${ }^{10}$ In order to be included in the sample, individuals must have no disability or other exemption as of September 2013. However, as both disability and exemption status can change over time, some of these individuals may have a prior history of disability or other exemptions. Similarly, individuals may be newly categorized as having a disability or another exemption after the reinstatement of work requirements (e.g. Figure C.11).
} 
Table 1: Descriptive Statistics of SNAP Enrollees in September 2013

\begin{tabular}{lrrrrr}
\hline & ABAWDs & \multicolumn{3}{c}{$\begin{array}{c}\text { Non-ABAWD } \\
\text { Adults }\end{array}$} \\
& & & & \\
& Mean & SD & Mean & SD \\
\hline Age & & & & \\
Female & 33.0 & 9.8 & 43.1 & 17.1 \\
Married & 0.40 & 0.49 & 0.67 & 0.47 \\
Household Size & 0.07 & 0.25 & 0.21 & 0.41 \\
Homeless & 1.32 & 0.69 & 2.59 & 1.62 \\
White & 0.14 & 0.34 & 0.02 & 0.13 \\
Black & 0.42 & 0.49 & 0.46 & 0.50 \\
Some College+ & 0.46 & 0.50 & 0.42 & 0.49 \\
Has Earned Income (DSS) & 0.10 & 0.30 & 0.12 & 0.33 \\
Has Unearned Income (DSS) & 0.17 & 0.37 & 0.26 & 0.44 \\
Avg. Annual Earnings (UI) & 0.07 & 0.26 & 0.41 & 0.49 \\
Fraction of Months Employed & 3,507 & 5,785 & 4,643 & 8,028 \\
& 0.32 & 0.34 & 0.31 & 0.39 \\
\hline Ever reported... & & & & \\
Any Disability & & & & \\
Exempt from Work Registration & 0.10 & 0.30 & 0.35 & 0.48 \\
Exempt due to Dependent & 0.39 & 0.49 & 0.77 & 0.42 \\
Medicaid Recipient & 0.11 & 0.31 & 0.32 & 0.46 \\
TANF Recipient & 0.43 & 0.50 & 0.78 & 0.41 \\
SNAP E\&T Participant & 0.12 & 0.32 & 0.24 & 0.43 \\
Moved County & 0.16 & 0.37 & 0.07 & 0.25 \\
\hline$N$ & 0.33 & 0.47 & 0.30 & 0.46 \\
\hline & 90,382 & 473,095 \\
\hline
\end{tabular}

Note: Table reports descriptive statistics of SNAP enrollees from September 2013. The top panel shows demographic data from DSS records, with the exception of the bottom three rows showing earnings and employment from UI records. Some College+ refers to educational attainment of some college or higher (college graduate or advanced degree). The bottom panel reports the fraction of people enrolled in September 2013 who had the designated indicator at any point since the start of the sample period (January 2007). 


\subsection{Falling Participation}

We begin by showing the acceleration of exit from SNAP when participants are confronted with work requirements. We use wide age ranges for these descriptive analyses, before subsequently focusing on narrower bandwidths around age 50 in the RD. The survival plot in Figure 1 shows the fraction of able-bodied adults who continue to be on SNAP for up to thirteen months after the start of their participation spell. The plot subsets to ABAWDs younger than 50, and adults 50 and older who would meet the criteria for ABAWD if not for their age. ${ }^{11}$ We also restrict attention to SNAP participants who first enter after the reinstatement of statewide work requirements between October 2013 and April 2014. For the first six months after entry, none of these participants are required to work in order to continue to receive SNAP benefits. Each month, a small fraction of participants leave SNAP for other reasons (e.g., income rising above the threshold) in equal proportions across the under-50 (dashed line with circles) and 50-and-above (solid line with triangles) groups.

After six months, those under 50 years old must demonstrate that they meet work requirements or be removed from program rolls. By contrast, those who are 50 or older have a light reporting requirement six months into their 12-month recertification period. While participation survival declines in both groups after six months due to reporting requirements (Gray 2019, Homonoff and Somerville 2019), the decline among those under 50 is much larger than the the corresponding decline for those 50 or older. ${ }^{12}$ By month seven, the surviving fraction of ABAWDs is more than 30 percentage points (over 40 percent) smaller than the surviving fraction of able-bodied adults aged 50 and older. Since the sample consists of SNAP participants who enter the program at different times over the course of several months, the sharp decline we observe among ABAWDs after six months is not explained by a common calendar-time shock. ${ }^{13}$

Next, we document the magnitude of total participation declines following the

\footnotetext{
${ }^{11}$ The under-50 group excludes 49 -year olds because they will pass the age-50 cutoff within the year.

${ }^{12}$ The sharper drop between the months we label as 6 and 7 than between the months we label as 5 and 6 is attributable to imperfect measurement. Because we only observe the month of initial entry, rather than the precise date, some of the participants in the plot do not actually face binding work requirements until the month we label as month 7 .

${ }^{13}$ The sharp drop tracks subsequent policy changes. Appendix Figure C.2 repeats the survival plot for later program entrants, those newly entering between July 2014 and December 2014, when the under-50 group was required to meet work requirements after only four months rather than after six months due to the shortening from 6-month recertification periods described in Section 2. The figure shows a remarkably similar pattern to Figure 1, with nearly identical survival curves for the under-50 and 50-and-above groups during the first four months, and then a sharp divergence after the under-50 group must meet work requirements. As a placebo test, Appendix Figure C.1 plots corresponding survival curves for the subset of counties that received exemptions from ABAWD work requirements in May 2014. Participation differs little by age when work requirements are not in effect. Taken together, these survival curves strongly suggest that work requirements reduced retention among new ABAWDs by substantial amounts.
} 
Figure 1: SNAP Participation Survival by Work Requirements Status

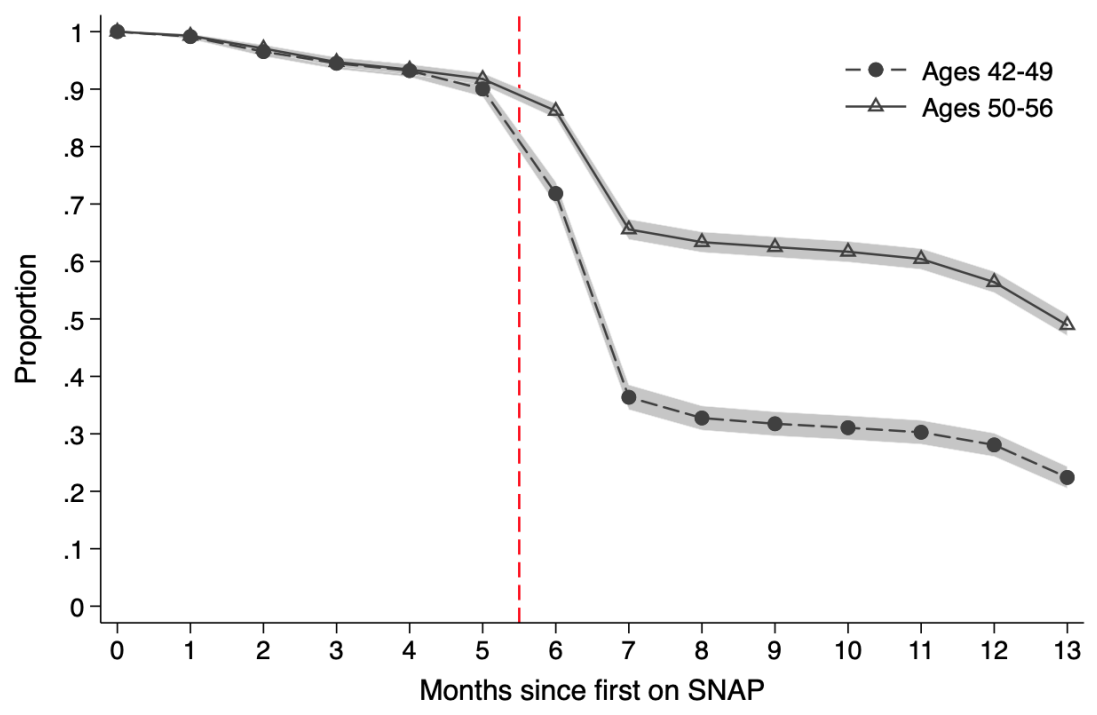

Notes: Figure plots participation survival for ABAWDs aged 42-49 and adults without dependents or disabilities aged 50-56 in counties with active work requirements, and who have not had a SNAP spell earlier in our sample period. Work requirements apply to ABAWDs (dashed line), who are required to start meeting them six months after initial entry (dashed red vertical line) in order to continue to receive SNAP benefits. Figure plots participation survival for participants whose SNAP spells begin between October 2013 and April 2014, prior to the gradual reduction in recertification period from six months to four months. Appendix Figure C.2 repeats this plot for those whose SNAP spells begin between July 2014 and December 2014, who are required to start meeting work requirements four months after initial entry. 
Figure 2: Total Participation Around Work Requirements

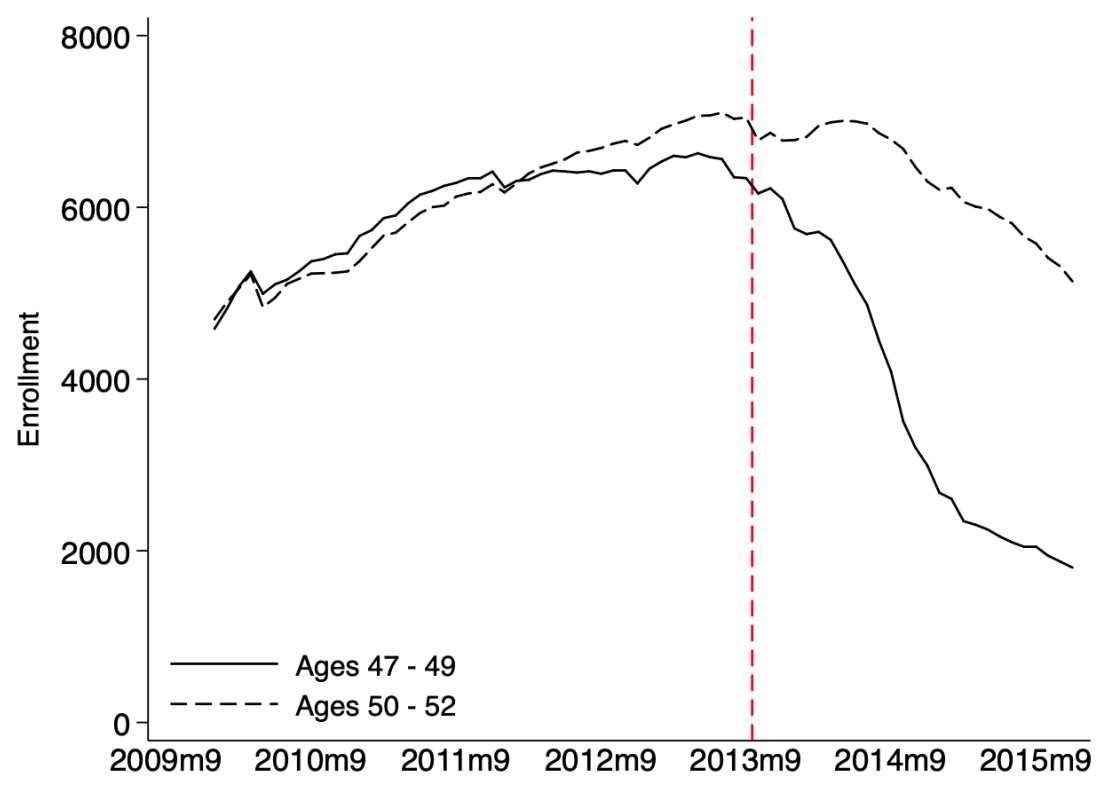

(a) Total Participation Counts (Raw)

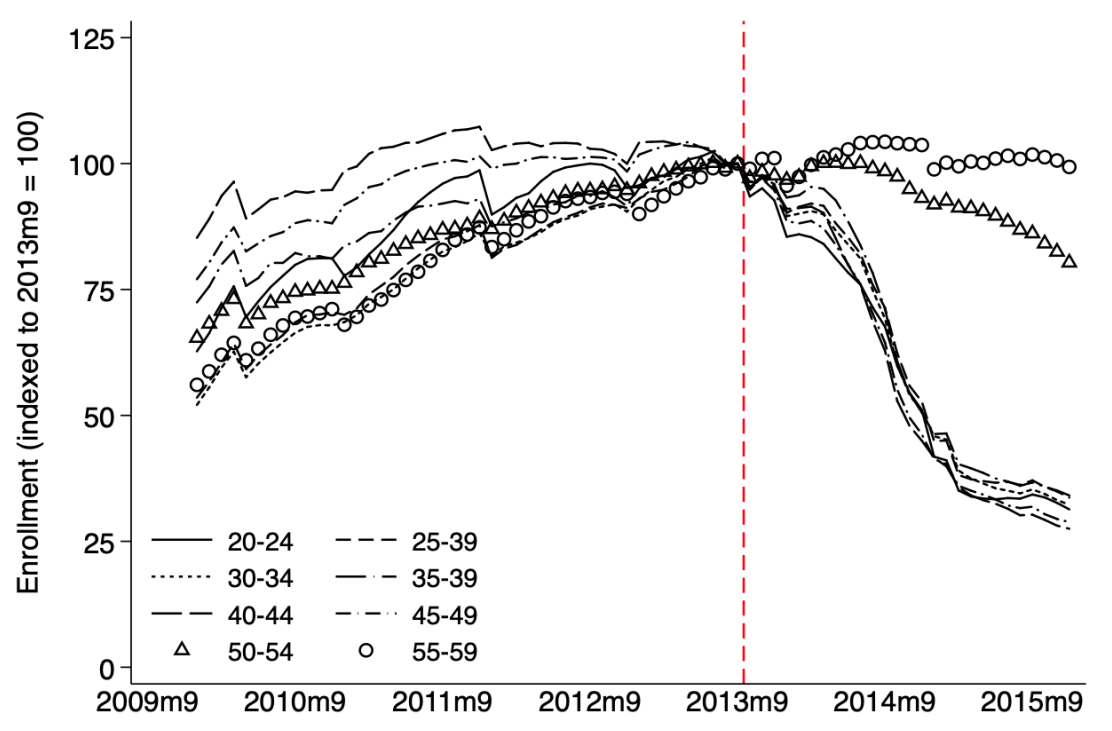

(b) Total Participation Counts (Normalized), By Age Group

Notes: Plots of monthly total participation counts in Virginia, for adults in the specified age ranges who would meet the definition for ABAWD if age were ignored. The dashed red vertical line corresponds to the end of the statewide ARRA exemptions from work requirements in September 2013. Top panel plots raw counts for age groups immediately surrounding age 50. Bottom panel plots counts for a wider range of age groups, normalized to within-group participation in September 2013. 
reintroduction of work requirements. Figure 2 a shows the total monthly participation counts before and after the reinstatement of work requirements (dashed red vertical line), comparing beneficiaries slightly younger than 50 (dashed line) to those 50 and slightly older (solid line). Across age groups, the participation increase that followed the Great Recession began to flatten and decline after 2012. After the reinstatement of work requirements, participation fell sharply among the under-50 group, whereas it remained stable for nearly a year in the 50-and-above group.

While our main RD identification strategy used in the next section estimates local average treatment effects for 50-year-old SNAP participants, Figure $2 \mathrm{~b}$ suggests that the participation effects we document may be generalizable to a broad range of ages. The figure plots participation counts for 5-year age bins, as a percentage of the corresponding age bin's count in September 2013 (just prior to the reinstatement of work requirements). While the groups aged 50 and above experience slow and heterogeneous declines in participation, all age ranges from 20 to 49 experience nearly identical relative declines in participation. The patterns in Figure 2b therefore suggest that the impact of work requirements on participation is likely fairly stable across the age distribution.

\subsection{Estimates of Total Participation Impact}

Section 3.1 shows that SNAP participation dropped differentially among participants subject to work requirements when work requirements were reinstated. However, potential underlying differences between the under-50 and 50-and-above groups make it difficult to draw conclusions about the portion of the differential drop, if any, that is caused by work requirements. To obtain a credible point estimate for the causal impact of work requirements on total participation, we exploit the sharp discontinuity in ABAWD classification at age 50 using a regression discontinuity framework.

We first estimate the impact of work requirements on total participation counts for the entire state of Virginia. ${ }^{14}$ Our preferred specification is a linear donut RD, with age (the running variable) centered around 50:

$$
Y_{a}=\alpha+\beta \cdot U 50_{a}+\gamma \cdot\left(a g e_{a}-50\right)+\delta \cdot U 50_{a} \cdot\left(a g e_{a}-50\right)+\varepsilon_{a}
$$

where $Y_{a}$ is the count of participants who, as of September 2013, are aged $a$, incremented in months. We follow Gelman and Imbens (2017) in using low-order polynomial specifications, with the local linear model as our preferred specification. Appendix $\mathrm{C}$ checks robustness

\footnotetext{
${ }^{14}$ Participation counts include only the 110 counties in which work requirements remain on after their reinstatement; the 23 counties that later regain exemptions are excluded.
} 
to alternative specifications. The variable $U 50_{a}$ is an indicator for whether age $a$ is strictly below 50, and therefore marks the age range where work requirements apply. The coefficient of interest is $\beta$, which measures the jump in the regression function at the discontinuity.

The primary specification estimates the model for participation counts eighteen months after the reinstatement of work requirements. This allows enough time to capture the entirety of the gradual roll-out of work requirements (described in Section 2.1). In evaluating outcomes at eighteen months, we exclude a donut of SNAP participants who are older than 48.5 and younger than 50 as of September 2013. As shown in Figure 3a, these participants cross the work requirements age cutoff between September 2013 and the period when outcomes are measured, and are therefore only partially exposed to work requirements. This age-out during the period between the policy change and the outcome measurement motivates the donut RD approach used throughout the paper. In order to avoid ad hoc bandwidth selection for the RDs, we follow the systematic procedure of Calonico et al. (2014) to select (potentially asymmetric) optimal bandwidths. ${ }^{15}$

Figure $3 \mathrm{~b}$ displays the results of the total participation donut RD. The sharp positive increase in participation at age 50 suggests that, eighteen months after reinstatement, work requirements reduce total ABAWD participation by 53 percent. This drop is calculated as the reduction within each monthly age bin (110.8 participants), compared to the number of participants at age 50 (205.4 participants).

Appendix Figure C.3 provides further evidence that the participation reduction is caused by work requirements. The figure shows the total participation RDs estimated at earlier periods: 12 months before the reinstatement of work requirements, the month that work requirements were reinstated, and 12 months after the reinstatement of work requirements. The periods before and at the reinstatement serve as placebo checks: participation on either side of the age 50 threshold is nearly identical, suggesting that the jump in Figure 3b is not attributable to discontinuities at age 50 that are present when work requirements are absent. The period 12 months after the reinstatement of work requirements shows a similar pattern to Figure 3b, but the participation drop below age 50 is smaller, consistent with the gradual roll-out of the policy. As further robustness checks, Appendix Figure C.4 plots the donut RD estimates for a wide array of time horizons using linear and quadratic specifications.

Before moving onto our main individual-level analysis using the stock population, we decompose the total SNAP participation decline into three distinct channels. The decline documented in Figure $3 \mathrm{~b}$ reflects some combination of increased exit among existing participants, faster exits among new participants entering after work requirements begin,

\footnotetext{
${ }^{15}$ Appendix Figure C.6 shows that our conclusions remain similar over a wide range of bandwidths.
} 
Figure 3: Exposure to Work Requirements and RD Estimate of Total Participation

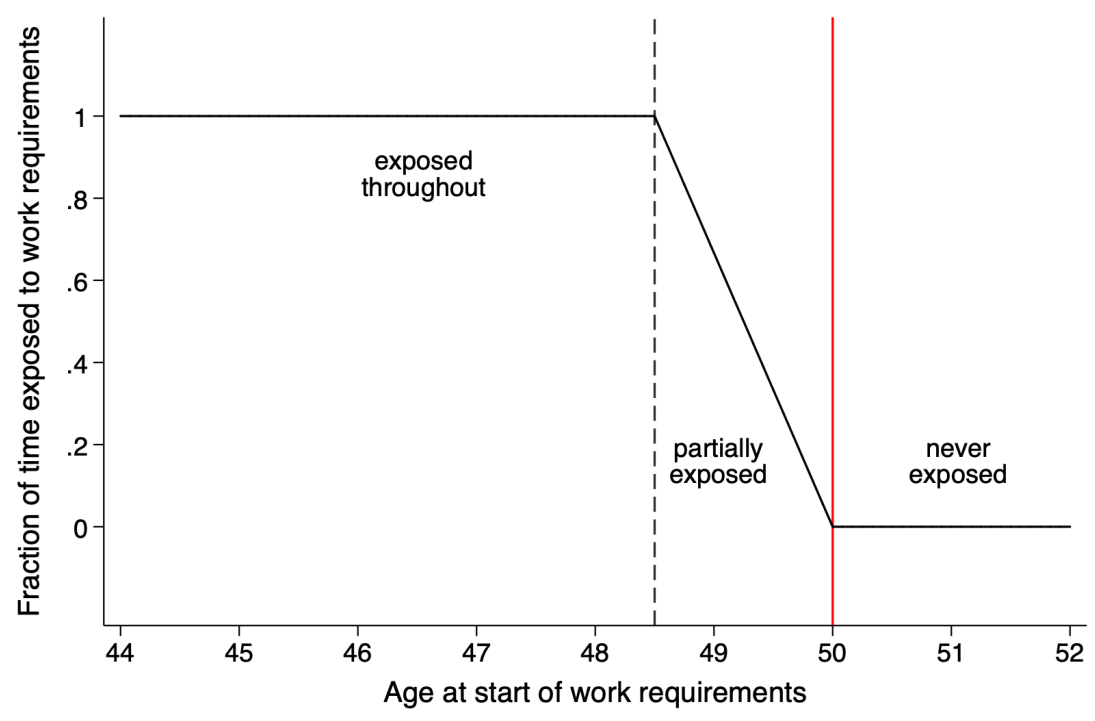

(a) Exposure to Work Requirements by Age at Start of Work Requirements

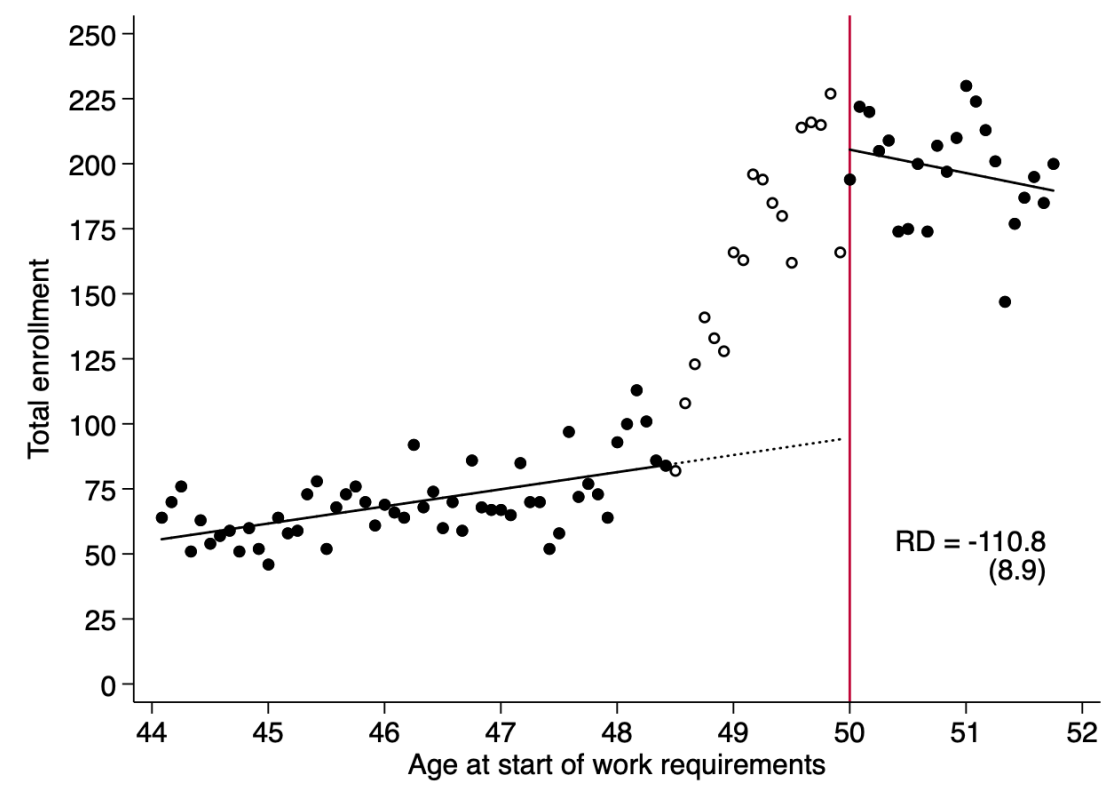

(b) RD Estimate of Total SNAP Participation, 18 Months After Work Requirements

Notes: Top panel shows the fraction of time that SNAP participants are subject to work requirements during the 18 months immediately following the reintroduction of work requirements. Work requirements abruptly cease to apply at age 50. Participants whose age when work requirements start is between 48.5 and 50 fall into the "donut" of those who age out by the time outcomes are measured (18 months after the reintroduction of work requirements). Bottom panel displays the donut RD results for total SNAP participation 18 months after work requirements were reinstated in Virginia. The scatter plot shows total participant counts by age in quarters, and the lines show a linear regression fit on both sides of the eligibility threshold. Standard errors clustered by monthly age in parentheses. The sample consists of the subset of counties for which work requirements remain on after October 2013. 
and deterrence of potential new participants who do not enter SNAP because of work requirements. We produce separate $\mathrm{RD}$ estimates for each channel, and then compare them to the missing mass of 110.8 beneficiaries per month from Figure $3 \mathrm{~b}$ to arrive at each channel's approximate contribution to the total enrollment decline. Table 2 summarizes the results of these exercises, which are described in detail in Appendix D.2. These exercises provide suggestive evidence that deterrence is not the primary driver of enrollment declines. Instead, the retentions of existing and new beneficiaries appear to be the most important channels driving total enrollment declines.

Table 2: Decomposition of Total Enrollment Declines in Figure 3b

\begin{tabular}{|c|c|c|c|}
\hline Mechanism & Exercise & $\begin{array}{c}\text { Explained \% of Enrollment } \\
\text { Decline }\end{array}$ & Details \\
\hline $\begin{array}{l}\text { Decreased retention } \\
\text { among existing } \\
\text { participants }\end{array}$ & $\begin{array}{l}\mathrm{RD} \text { of retention for existing } \\
\text { enrollees (main analysis) }\end{array}$ & $\begin{array}{c}48 \% \\
(\mathrm{RD} \text { estimate } \times \text { num. of } \\
\text { 50y.o. enrollees }=53)\end{array}$ & $\begin{array}{l}\text { Figure } 4 \mathrm{a} ; \\
\text { Section } 4.2\end{array}$ \\
\hline $\begin{array}{l}\text { Decreased retention } \\
\text { among new } \\
\text { enrollees }\end{array}$ & $\begin{array}{l}\text { RDs of retention for each } \\
\text { monthly cohort of new } \\
\text { entrants from October } 2013 \\
\text { through March } 2015\end{array}$ & $\begin{array}{c}18 \% \\
(\text { sum of RD estimates }=20)\end{array}$ & $\begin{array}{l}\text { Appendix } \\
\text { Figure D.1 }\end{array}$ \\
\hline $\begin{array}{l}\text { Deterrence of } \\
\text { potential new } \\
\text { enrollees }\end{array}$ & $\begin{array}{l}\text { RDs of total new enrollment } \\
\text { in each month from October } \\
2013 \text { through March } 2015\end{array}$ & $\begin{array}{c}15 \% \\
(\text { sum of RD estimates }=16)\end{array}$ & $\begin{array}{c}\text { Appendix } \\
\text { Figure D.2 }\end{array}$ \\
\hline
\end{tabular}

\section{Effects on Participant Exit}

This section estimates the effect of introducing work requirements on the retention of existing beneficiaries. The regressions are estimated on our "stock" population of childless adults who were participating in SNAP as of September 2013, just before the reinstatement of work requirements. The stock population has three attractive features. First, it defines the sample prior to the reinstatement of work requirements, thereby avoiding selection issues arising from nonrandom work requirement-induced deterrence of entry into SNAP. Second, it better limits the analyzed population to those who are likely to be impacted by SNAP policy changes, bringing the estimate closer to treatment-on-the-treated than studies that use cross-sectional survey data. Third, it allows us to study the heterogeneity of work requirements using individuals' ex ante characteristics. We only include individuals from the counties in which work requirements remained in force for two or more years after their reinstatement, which covers 70.7 percent of the full stock sample. This sample definition 
allows us to measure outcomes for all participants after the same elapsed time since the reinstatement of work requirements. This is our main sample for the remainder of the paper.

As before, our preferred donut RD specification is a local linear model, with age centered around 50:

$$
Y_{i}=\alpha+\beta \cdot U 50_{i}+\gamma \cdot\left(a g e_{i}-50\right)+\delta \cdot U 50_{i} \cdot\left(a g e_{i}-50\right)+\eta \cdot X_{i}+\varepsilon_{i}
$$

where $Y_{i}$ is our outcome of interest for individual $i$ in a predetermined future month. The coefficient of interest is $\beta$, which measures the jump in the regression function at the discontinuity. We begin by running these regressions on our stock population, and examine outcomes after the October 2013 reinstatement of work requirements.

The vector $X_{i}$ includes a handful of individual-level controls to increase precision; point estimates are very similar with or without controls. The baseline specification includes indicators for female, married, homelessness, any earned income, any unearned income, some college, race, and household size from SNAP records. It also includes pre-period (January 2007 to September 2013) wage earnings, and the fraction of months with employment in the pre-period from the UI records. Covariates from SNAP records are measured at the last recertification prior to September 2013.

As before, our main specifications measure outcomes eighteen months after work requirements resume (March 2015), with an excluded donut of SNAP participants who are only partially exposed to work requirements between September 2013 and March 2015 (see Figure 3a). Standard errors are clustered by monthly age (the discrete running variable). Again, our main results use MSE-optimal bandwidths determined by the method in Calonico et al. (2014).

\subsection{Identification Assumptions}

The identification assumptions for these RD regressions of participant exit are analogous to the assumptions required for the labor market outcomes RD regressions in Section 5. We therefore discuss both together here. The key identification assumption of the donut RD is that the potential outcomes would have evolved smoothly through the excluded donut in the absence of the treatment that starts at age 50. This assumption is more demanding than the standard RD assumption that the potential outcomes would have been smooth at the age 50 cutoff that determined treatment.

We perform a battery of checks to validate the research design. First, we test for balance in covariates at the discontinuity by replacing our outcome variable, $Y_{i}$, with each of our demographic controls. Table 3 shows there are rarely significant differences across 
the threshold, except on the dimensions of marital status and racial composition. These differences, however, are not statistically significant after correcting for multiple tests. ${ }^{16}$ Second, we verify that the density of the age distribution is smooth at the discontinuity. Appendix Figure C.7 shows there is no visual evidence of sorting around the cutoff. We fail to reject the null hypothesis of continuity in the density at age 50 based on the manipulation tests in Frandsen (2017), which adapts the standard density tests for a discrete running variable (McCrary 2008, Cattaneo et al. 2018). Finally, we estimate a "placebo" RD using outcomes from the ARRA time period when work requirements were not in effect for any group. We find no "effect" of the age 50 threshold on enrollment or employment in the placebo period (Figures 4b, 5b, and 6b). We also estimate these regressions in the placebo period without excluding ages in the donut to check for violations of the donut RD assumption, and find precisely estimated zeros, as in the main placebo regressions. ${ }^{17}$ These checks support the identifying assumptions required for the validity of the research design. ${ }^{18}$

\subsection{Estimates of Participant Exit}

Figure 4a displays our main donut RD results with the outcome defined as an indicator for whether an individual from our stock population participates in SNAP eighteen months after the reinstatement of work requirements. The figure displays a fitted regression as well as average retention percentages, with age collapsed to quarters for readability. The sharp positive increase in participation at age 50 suggests that work requirements reduce ABAWD participation by a statistically significant 23.4 percentage points. This represents a 37 percent decline from the mean among participants aged 50. As further evidence that this decline is a result of work requirements, Figure $4 \mathrm{~b}$ replicates the specification using data from the statewide ARRA exemption period between 2011 and 2013, when all participants were exempt from work requirements. This placebo regression uses an analogous "stock" sample of participants enrolled in September 2011 and measures outcomes in March 2013, matching the calendar months of our main stock sample to address seasonality. There is no

\footnotetext{
${ }^{16}$ Table 3 does not include a donut. Appendix Table C.5 presents the corresponding balance table including an 18-month donut.

${ }^{17}$ The key coefficient of interest (standard error) in the placebo period is -0.001 (0.020) excluding observations in the donut and -0.0003 (0.014) otherwise for the enrollment outcome. For the employment outcome, the corresponding coefficient is 0.007 (0.012) excluding the donut and $0.002(0.010)$ otherwise. These are small relative to their respective means reported in Table 5.

${ }^{18} \mathrm{We}$ also estimate an alternative specification using regression kink (RK) designs to include the data between ages 48.5 and 50, as described in Appendix D.3. We continue to estimate statistically significant negative effects of work requirements, but while the magnitudes are not statistically distinguishable from our main results, data limitations and noisy estimates prevent strong conclusions using this approach.
} 
Table 3: Covariate Balance in RD

\begin{tabular}{|c|c|c|c|c|c|}
\hline & Discontinuity & S.E. & Control Mean & $\%$ diff & $N$ \\
\hline Female & -0.006 & 0.019 & 0.459 & -1.3 & 14,331 \\
\hline White & -0.025 & 0.014 & 0.414 & -6.0 & 15,313 \\
\hline Black & 0.037 & 0.015 & 0.421 & 8.8 & 15,476 \\
\hline Married & 0.022 & 0.008 & 0.096 & 22.5 & 21,333 \\
\hline Household Size & 0.019 & 0.016 & 1.246 & 1.5 & 18,703 \\
\hline Household Head & -0.008 & 0.007 & 0.932 & -0.9 & 14,547 \\
\hline Homeless & 0.015 & 0.010 & 0.131 & 11.7 & 21,359 \\
\hline High School & 0.010 & 0.014 & 0.538 & 1.8 & 21,369 \\
\hline Some College or Higher & -0.007 & 0.010 & 0.110 & -5.9 & 18,554 \\
\hline Has Earned Income & -0.008 & 0.008 & 0.176 & -4.7 & 14,715 \\
\hline Has Unearned Income & 0.006 & 0.007 & 0.091 & 6.7 & 18,897 \\
\hline Earned or Unearned Income & 0.006 & 0.010 & 0.250 & 2.5 & 15,679 \\
\hline Fraction of Months Employed, 7yr avg & -0.002 & 0.011 & 0.351 & -0.7 & 14,144 \\
\hline Avg. Annual Earnings, $7 y r$ avg & 135.249 & 251.041 & 6482.530 & 2.1 & 18,440 \\
\hline Fraction of Months Employed, 3yr avg & -0.006 & 0.012 & 0.281 & -2.2 & 14,722 \\
\hline Avg. Annual Earnings, 3yr avg & -219.885 & 224.021 & 4292.832 & -5.1 & 18,525 \\
\hline Number of Months on SNAP & 0.685 & 0.725 & 27.022 & 2.5 & 18,115 \\
\hline Unemployment rate & 0.006 & 0.024 & 5.820 & 0.1 & 16,662 \\
\hline
\end{tabular}

Notes: Table presents balance tests of covariates at SNAP enrollment using our "stock" sample. Each row corresponds to a separate regression with that characteristic as the dependent variable, without controls. The discontinuity measures the jump in the regression function at age 50. Standard errors are clustered by monthly age (the running variable). Earnings measures are winsorized at the 99th percentile. The Control Mean denotes the mean of that characteristic immediately to the right of age 50. Each regression uses MSEoptimal bandwidths calculated separately for each side of the cutoff and for each outcome, and a uniform kernel to weight observations. Sample sizes vary depending on the bandwidth used. 
statistically or economically significant difference in participation across the age 50 cutoff during this placebo period.

Appendix Figure C.5 traces out the donut RD results for participation where outcomes are measured at alternative time periods, ranging from 1 to 27 months following the reinstatement of work requirements. The effect begins to appear in the seventh month after work requirements resume, which is the first month that we should expect SNAP participants to be disenrolled if they were not meeting the requirements. The participation drop reaches 24 percentage points within roughly eighteen months and then declines slightly thereafter, consistent with the disenrollment schedule described in Section 2.1.

Program exit due to work requirement policy can occur through at least two distinct channels, which we decompose here. First, SNAP participants may exit as a result of failure or unwillingness to work or perform other qualifying activities. Second, participants may exit due to a more demanding recertification schedule, given the 6-month grace period associated with Virginia's policy. We can isolate the first channel by looking only at a subset of stock population participants who share the same recertification burdens regardless of age. Specifically, all participants under 50 as of September 2013 must complete two recertifications in the 18 months between September 2013 and March 2015. Participants 50 and older with initial enrollment between October and March also face two recertifications over this period. Yet participants over 50 whose enrollment spells began between April and September must only complete one recertification in the 18 months following September 2013.

This variation in recertification requirements by month applies irrespective of the year in which the enrollment spell begins. For example, consider two 50-year-old non-working beneficiaries with recertifications due in March and April, respectively. The March recertifier must submit paperwork in March 2014 and March 2015 while the April recertifier must submit paperwork in April 2014 and April 2015, which is one month past the 18-month window. By the time we assess retention in March 2015, the March recertifier must have submitted two rounds of paperwork, while the April recertifier must have submitted one. Appendix Figure C.8 shows the RD estimate only for those in the stock population who have scheduled recertifications in the months of September 2013 through March 2014. These participants are scheduled to undergo two recertifications by March 2015, regardless of their age in September 2013. The RD estimate of 24.8 percentage points is not statistically distinguishable from the main estimate of 23.4 percentage points in this section. The limited impact of this extra recertification step is not surprising, given that most SNAP participants either miss all recertifications or successfully complete numerous recertifications in a row (Hastings and Shapiro 2018, Gray 2019). That we find no significant difference in participation as a function of number of recertifications 
Figure 4: RD Estimates of SNAP Retention, 18 Months After Work Requirements

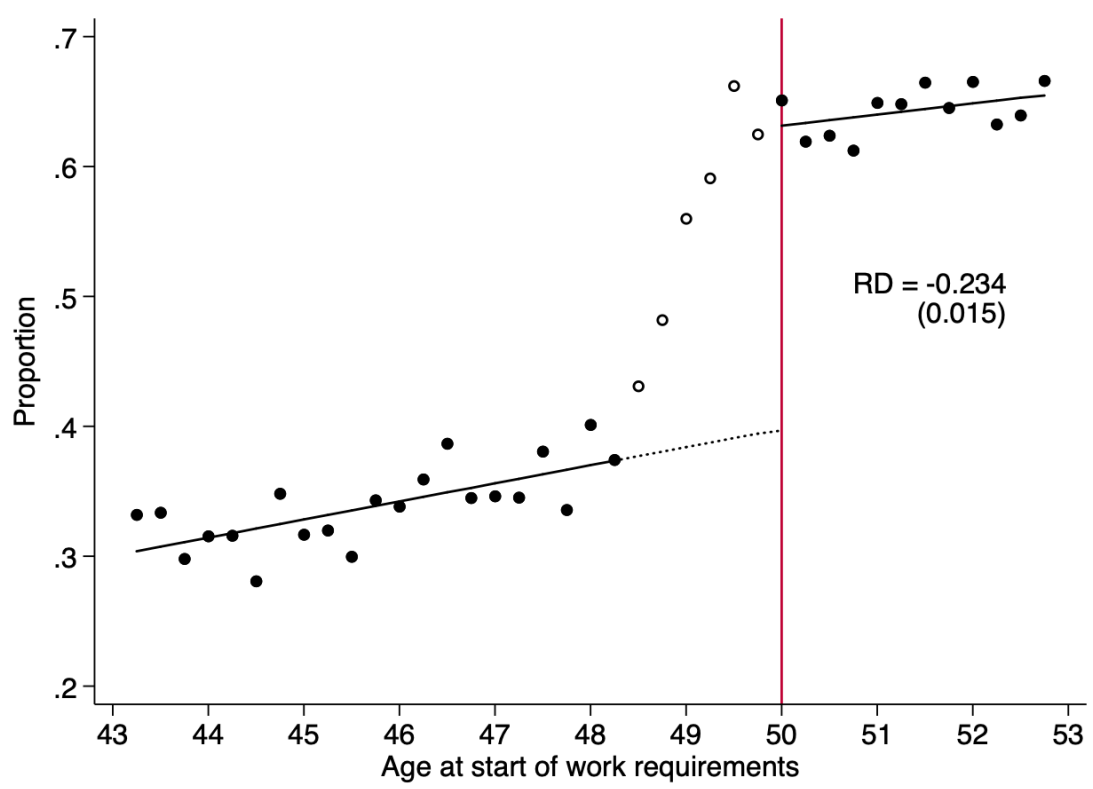

(a) Participation During Work Requirements

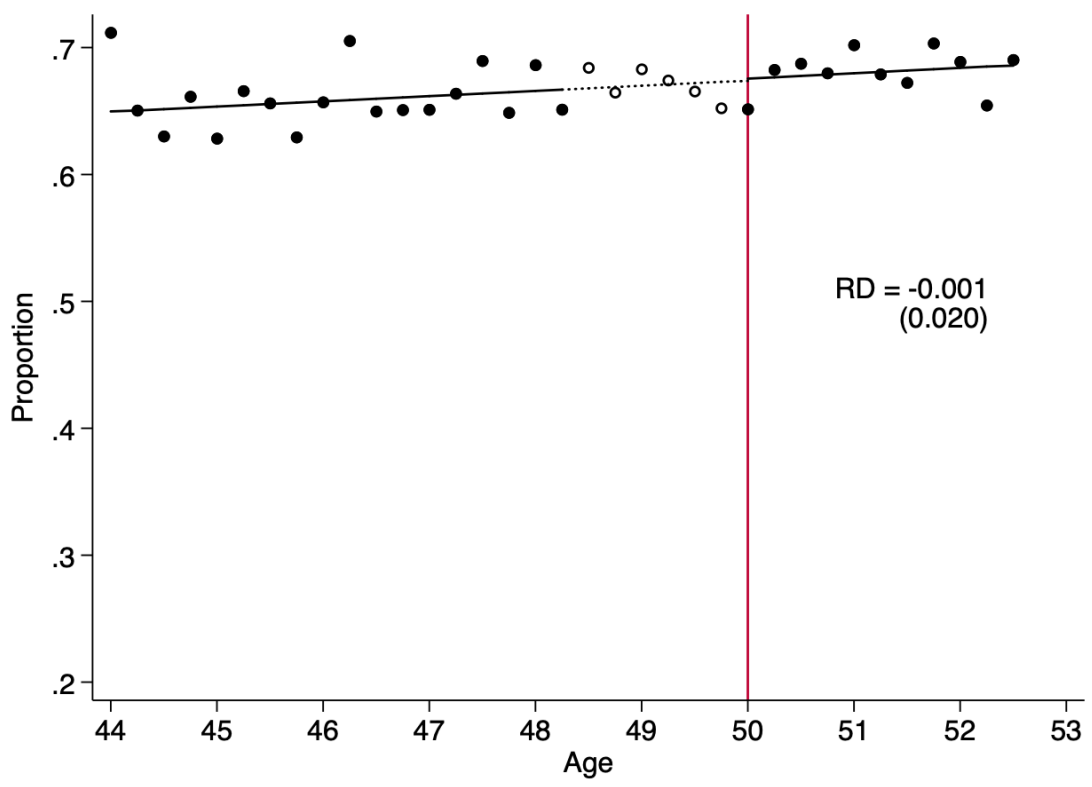

(b) Placebo Test: Participation During ARRA Exemptions

Notes: Panel (a) visually displays the RD results for SNAP participation after eighteen months of work requirements. The scatter plot shows covariate-adjusted means by age in quarters, and the lines show a linear regression fit in months on both sides of the eligibility threshold. Standard errors clustered by monthly age in parentheses. The sample consists of work-registered individuals on SNAP in September 2013 and in the subset of counties for which work requirements remain on after October 2013. As a placebo test, Panel (b) replicates the analysis among those enrolled in September 2011 and measures enrollment in March 2013, over which period no work requirements were in effect. 
confirms that the failure to meet work requirements, and not the extra recertification associated with work requirements in Virginia, is the primary driver of our results.

\subsection{Heterogeneous and Screening Effects of Work Requirements}

Section 4.2 documents that work requirements lead to substantial exit from SNAP. This section examines who exits from SNAP as a result of work requirements using two alternative measures. First, to assess whether participants with certain characteristics are more sensitive to work requirements, we fully interact the standard RD specification with an indicator for observable binary characteristic $x$. The $x$ characteristics are captured in September 2013. We estimate the following specification:

$$
\begin{aligned}
Y_{i} & =\alpha_{1}+\alpha_{2} x_{i}+\beta_{1} U 50_{i}+\beta_{2} U 50_{i} \cdot x_{i}+\gamma_{1}\left(a g e_{i}-50\right)+\gamma_{2}\left(a g e_{i}-50\right) \cdot x_{i} \\
& +\delta_{1}\left(a g e_{i}-50\right) \cdot U 50_{i}+\delta_{2}\left(a g e_{i}-50\right) \cdot U 50 \cdot x_{i}+\varepsilon_{i}
\end{aligned}
$$

where $Y_{i}$ is an indicator for participation in SNAP of individual $i$ from our stock population eighteen months after the reinstatement of work requirements. Observable characteristics $x$ include several of the demographic variables previously introduced in the text and variables indicating above-median time spent on SNAP (either over the lifetime of individuals as captured in our data or in their most recent spells). We also create an earnings "index" by predicting earnings from a regression of 2013Q3 earnings against these our other demographic variables. $\quad \alpha_{1}$ estimates the SNAP program eighteen-month retention rate for those without characteristic $x$. $\beta_{1}$ estimates the corresponding impact of work requirements on this retention rate in percentage points. The new coefficient $\beta_{2}$ estimates how much larger the discontinuity is for those with a given characteristic $\left(x_{i}=1\right)$, as a percent of all members of the "stock" population with that characteristic.

We scale the effect of work requirements on retention among those with $x_{i}=0$ by the baseline retention rate absent work requirements $\left(\frac{\beta_{1}}{\alpha_{1}}\right)$ in order to construct more interpretable parameters. We then perform the analogous scaling for those with $x_{i}=1$ as $\left(\frac{\beta_{1}+\beta_{2}}{\alpha_{1}+\alpha_{2}}\right)$. These numbers capture the fraction of participants who left the program due to work requirements out of those who would have been on the program absent work requirements. They therefore have a more intuitive interpretation as the sensitivity of participants to work requirements.

Estimates of $\beta_{2},\left(\frac{\beta_{1}}{\alpha_{1}}\right)$ and $\left(\frac{\beta_{1}+\beta_{2}}{\alpha_{1}+\alpha_{2}}\right)$ are reported in columns 1, 2 and 3 of Table 4, respectively. Each row in Table 4 refers to estimates from a separate regression corresponding 
Table 4: Sensitivity RD, 18 Months After Work Requirements

\begin{tabular}{|c|c|c|c|c|}
\hline & $\beta_{2}$ & $\beta_{1} / \alpha_{1}$ & $\frac{\beta_{1}+\beta_{2}}{\alpha_{1}+\alpha_{2}}$ & $\begin{array}{c}p \text {-value } \\
\text { of difference }\end{array}$ \\
\hline Above Median Earnings Index & $\begin{array}{c}0.048 \\
(0.029)\end{array}$ & -0.400 & -0.365 & 0.345 \\
\hline Female & $\begin{array}{c}0.062 \\
(0.035)\end{array}$ & -0.446 & -0.325 & 0.007 \\
\hline Married & $\begin{array}{c}0.068 \\
(0.067)\end{array}$ & -0.396 & -0.316 & 0.432 \\
\hline Homeless & $\begin{array}{l}-0.140 \\
(0.040)\end{array}$ & -0.357 & -0.559 & 0.000 \\
\hline White & $\begin{array}{c}0.034 \\
(0.026)\end{array}$ & -0.407 & -0.361 & 0.238 \\
\hline Black & $\begin{array}{l}-0.058 \\
(0.035)\end{array}$ & -0.367 & -0.417 & 0.296 \\
\hline Some College+ & $\begin{array}{c}0.015 \\
(0.052)\end{array}$ & -0.387 & -0.416 & 0.700 \\
\hline Has Earned Income & $\begin{array}{c}0.096 \\
(0.035)\end{array}$ & -0.414 & -0.273 & 0.006 \\
\hline Has Unearned Income & $\begin{array}{c}0.102 \\
(0.061)\end{array}$ & -0.401 & -0.260 & 0.111 \\
\hline Ever Before UI Recipient & $\begin{array}{c}0.030 \\
(0.050)\end{array}$ & -0.392 & -0.374 & 0.771 \\
\hline Ever Before Disability & $\begin{array}{c}0.190 \\
(0.041)\end{array}$ & -0.476 & -0.122 & 0.000 \\
\hline Above Median Unemployment Rate & $\begin{array}{l}-0.022 \\
(0.031)\end{array}$ & -0.386 & -0.394 & 0.843 \\
\hline Above Median Previous Time on SNAP & $\begin{array}{l}-0.091 \\
(0.036)\end{array}$ & -0.381 & -0.399 & 0.696 \\
\hline Above Median Previous SNAP Spell & $\begin{array}{l}-0.119 \\
(0.030)\end{array}$ & -0.346 & -0.410 & 0.152 \\
\hline
\end{tabular}

Notes: Table presents RD estimates of Equation 3. Each row presents results from a separate regression corresponding to the characteristic listed. Separate MSE-optimal bandwidths calculated on each side of the donut. The column $\beta_{2}$ presents the differential jump at age 50 for people with the characteristic relative to those without. Standard errors clustered by monthly age in parentheses. The second column reports the retention of people without the characteristic, calculated as $\beta_{1} / \alpha_{1}$. The third column reports retention for those with the characteristic, calculated as $\left(\beta_{1}+\beta_{2}\right) /\left(\alpha+\alpha_{2}\right)$. The $p$-value from the test that columns 2 and 3 are equal is reported in the last column, calculated using the delta method. 
to a different characteristic $x$. We use the delta method to evaluate whether $\left(\frac{\beta_{1}}{\alpha_{1}}\right)$ and $\left(\frac{\beta_{1}+\beta_{2}}{\alpha_{1}+\alpha_{2}}\right)$ are statistically different, and report the $p$-value in column 4 . Greater sensitivity to work requirements among the group with characteristic $x$ in comparison to the group without characteristic $x$ is indicated by a negative and statistically significant estimate of $\beta_{2}$ (column 1), or a larger negative value of $\left(\frac{\beta_{1}+\beta_{2}}{\alpha_{1}+\alpha_{2}}\right)$ (column 3) compared to $\left(\frac{\beta_{1}}{\alpha_{1}}\right)$ (column 2) and a statistically significant $p$-value (column 4 ). We find that work requirements have disproportionately larger impacts on participants who are homeless, participants without earned income, and men. On the other hand, those who have a history of reporting a disability are less likely to be impacted by work requirements. This group may be more likely to be reclassified as exempt from work requirements due to not meeting the definition for able-bodied. Appendix Figure C.11 shows that an additional 5.6 percent of the stock population stay on the program by claiming a new exemption.

We repeat these analyses using a second screening measure that describes how the composition of retained participants is affected by work requirements. This measure captures changes due to work requirements in the characteristics of the population of SNAP participants, rather than the differential group-specific exit sensitivities captured by our first measure. Results may differ from those using the first measure when the number of people with a given characteristic is small. In such cases, even large sensitivities may translate to very small compositional changes in the pool of SNAP participants. The findings using this compositional measure of screening are similar to the findings in Table 4. Work requirements reduce the proportion of homeless individuals and individuals with no earned income among those who remain on SNAP; and increase the proportion of those who have a documented history of disability. The details of this measure are described in Appendix D.4. Overall, the results suggest that work requirements disproportionately impact beneficiaries with characteristics suggesting greater economic vulnerability, while disproportionately exempting those with a history of disability.

\section{$5 \quad$ Effects on Labor Market Outcomes}

This section estimates the effect of work requirements on individual-level labor market outcomes using the stock population and regression specification described in Section 4. We first present estimates of the effects on employment, wage earnings, and other labor market outcomes. We then conduct robustness checks for both the employment and earnings estimates. Finally, we estimate RDs on quantiles of the earnings distribution to 
examine heterogeneity in the labor market impacts of work requirements.

\subsection{Estimates of Labor Market Effects}

Section 3.2 documents the large participation drops due to work requirements. In contrast, this section shows that the average effects on employment and earnings are small in magnitude and not statistically different from zero. Figure 5 shows the donut RD results with an indicator for employment as the dependent variable, defined as having any UI-covered earnings six quarters after work requirements were reinstated. This regression uses the same controls as Equation 2, and the same MSE-optimal bandwidth selection procedure. We fail to detect a statistically significant impact of work requirements on employment on average, and we statistically reject employment increases larger than 3.5 percentage points. We find nearly identical results in the placebo period. To test robustness, Appendix Figure C.9 defines the dependent variable as the union of having a wage in the UI data or reporting earned income to the SNAP agency. This allows us to capture possible effects on self-employment, under the assumption that work requirements only induce additional self-employment if the affected individuals remain on SNAP. The point estimates are nearly identical and still not statistically different from zero. Furthermore, the donut RD may overstate any employment effect if younger SNAP recipients exit SNAP more quickly than older recipients due to the improving economy. The time series patterns by age in Figure 2a suggest this possibility, which reinforces our interpretation of a very small average employment effect.

A potential explanation for this null result is that many SNAP participants have very low labor force attachment, making employment responses unlikely and diluting the average estimate. We further investigate this null result in Appendix Table C.4, which shows our primary specification using individuals with greater or lesser labor force attachment. To measure labor force attachment, we predict UI-covered employment in the third quarter of 2013 with LASSO regression, using a large set of demographic covariates. ${ }^{19}$ Work requirements do not clearly increase UI-covered employment even for individuals who we predict to have moderate or strong pre-existing attachment to the labor force.

We then assess whether UI-covered earnings change at the age 50 cutoff. Figure 6 a

\footnotetext{
${ }^{19}$ Specifically, we use data-dependent penalization methods based on Belloni et al. (2012). The regression includes the following controls to predict employment: indicators for yearly age, indicators for earnings in each month of the previous 7 years prior to Sept. 2013, household size, and indicators for gender, married, private living arrangement, white, black, some college or higher education, reporting earned income on the SNAP application, and reporting unearned income on the SNAP application. In predicting employment probabilities, we randomly divide the sample into fifths and use data from four-fifths to fit a model to predict employment in the remaining fifth.
} 
Figure 5: RD Estimates of Employment, 18 Months After Work Requirements

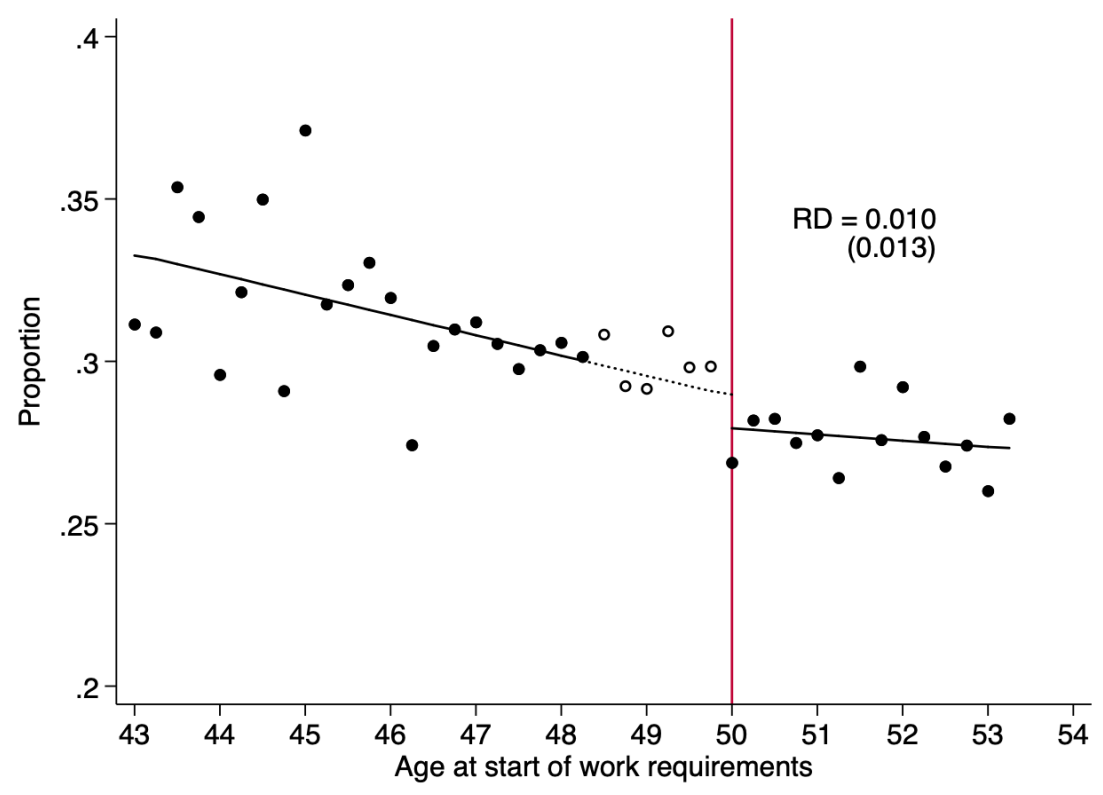

(a) Employment During Work Requirements

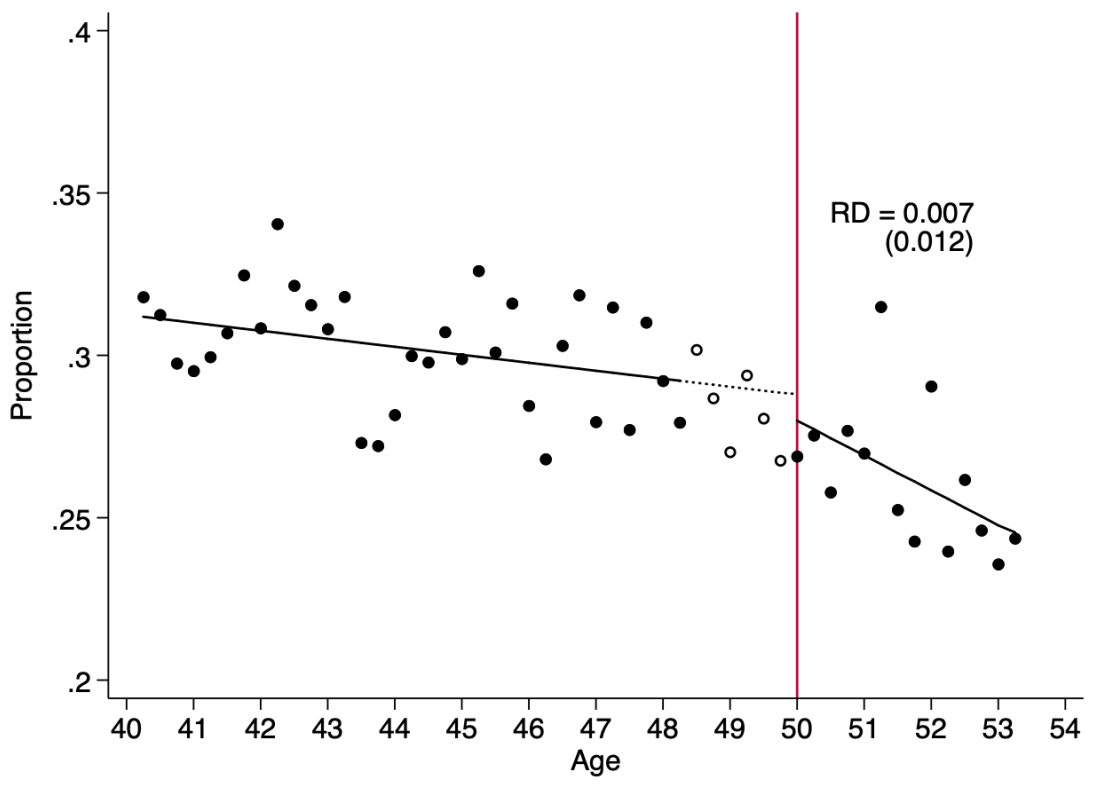

(b) Placebo Test: Employment During ARRA Exemptions

Notes: Panel (a) visually displays the RD results for employment after eighteen months of work requirements. The scatter plot shows covariate-adjusted means by age in quarters, and the lines show a linear regression fit in months on both sides of the eligibility threshold. Standard errors clustered by monthly age in parentheses. The sample consists of work-registered individuals on SNAP in September 2013 and in the subset of counties where work requirements remain on after October 2013. Panel (b) replicates the same analysis among those enrolled in September 2011, when the ARRA exemption that suspended work requirements was in effect for an additional two years. 
shows no statistically significant impact on average earnings. While the estimate is somewhat imprecise, we are able to statistically rule out increases over $\$ 28$ per month. Appendix Figure C.10a shows qualitatively similar results for log earnings. We also find imprecise estimates by different levels of labor force attachment, as shown in Appendix Table C.4.

Table 5 summarizes the point estimates and standard errors of interest from the donut RDs described in the preceding two sections. Below the coefficient estimates, we report the mean of each corresponding outcome variable at age 50 (immediately to the right of the RD threshold). For the two outcomes where we find statistically significant effects in our main stock sample, the estimate from the placebo period is a precisely estimated zero. Overall, the findings suggest that work requirements do not increase labor force attachment by a meaningful amount on average eighteen months after their reinstatement despite a very large corresponding drop in SNAP participation.

A number of robustness checks in Appendix $\mathrm{C}$ also fail to find strong evidence of employment effects. Appendix Figure C.6 shows robustness to alternative bandwidth choices for employment and earnings, using a symmetric bandwidth on both sides of the cutoff. Appendix Figure C.12 presents estimates for other durations ranging from 1 to 27 months after work requirements. We also obtain similar estimates if we use triangular kernels instead of a uniform kernel to weight observations (Appendix Table C.2). We reproduce Table 5 without covariates in Appendix Table C.3. The estimates on employment and earnings are slightly higher, but still not close to statistical significance. Appendix Figure C.13 plots these estimates over time to examine robustness to the choice of duration. While there are signs of an upward trend in both employment and earnings, none of the estimates are statistically significant and they remain within the confidence intervals for models with controls (Appendix Figure C.12). ${ }^{20}$ Collectively, these results reinforce that our findings are consistent with zero or moderate average impacts on employment or earnings.

Although our null results for earnings are consistent with some small estimates of earnings elasticities from the literature, they are inconsistent with the much larger elasticity estimates in populations similar to our sample. Typical estimates in the literature range from -0.1 to 0 (Imbens et al. 2001, McClelland and Mok 2012, Cesarini et al. 2017). However, these estimates come from populations with substantially higher incomes than our sample. Less than one third of 50-year-old ABAWDs are employed. Papers studying populations more similar to our sample imply substantially higher income elasticities: Gelber et al. (2017) report an earnings decline of $\$ 0.20$ for every $\$ 1$ increase in SSDI benefits, and Deshpande (2016) reports a dollar-for-dollar parental earnings response to SSI benefits for children. In light of these larger estimates, our null results might be viewed as surprising. Our results

\footnotetext{
${ }^{20}$ Appendix D.3 presents corresponding regression kink estimates and also yields statistical zeros.
} 
Figure 6: RD Estimates of Earnings, 18 Months After Work Requirements

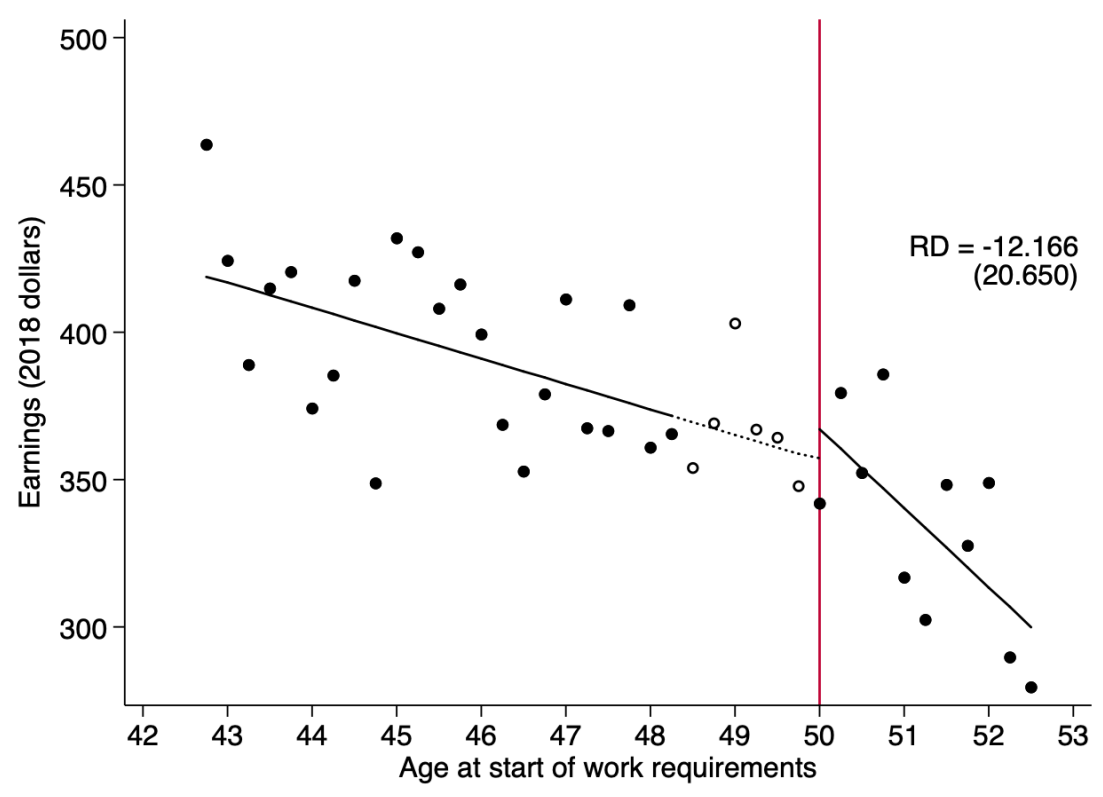

(a) Earnings During Work Requirements

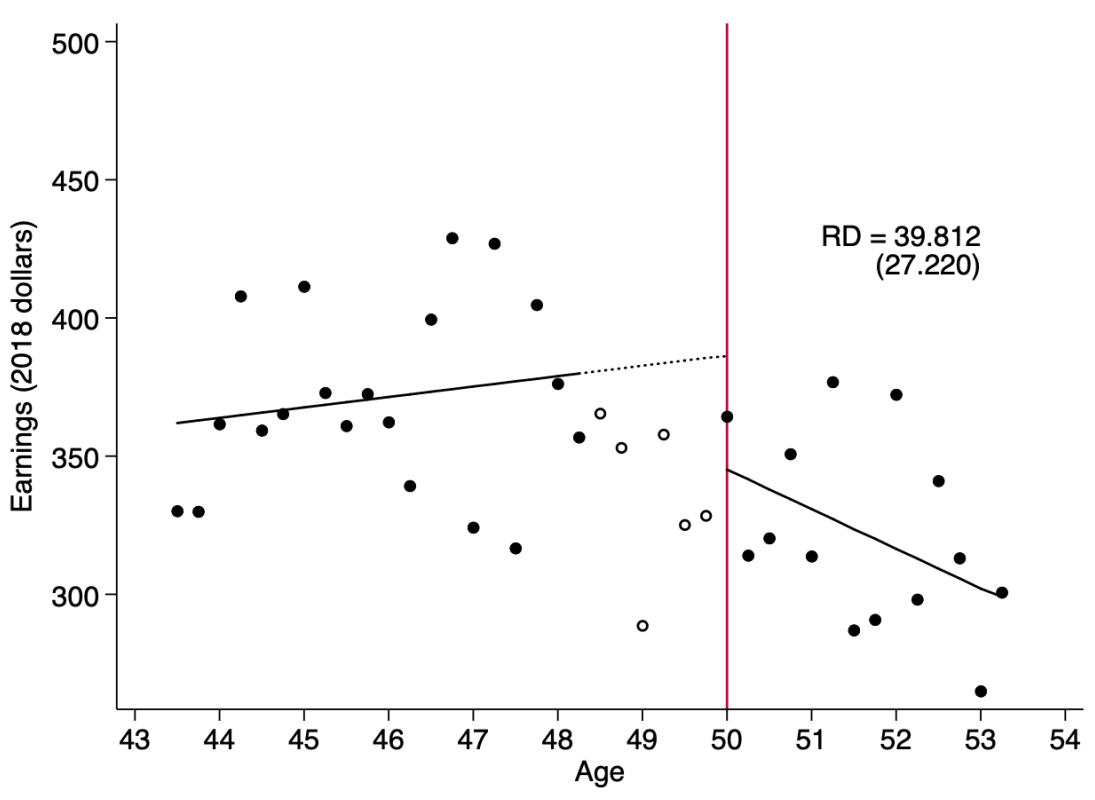

(b) Placebo Test: Earnings During ARRA Exemptions

Notes: Panel (a) visually displays the RD results for earnings (including zeros) after eighteen months of work requirements. Earnings are top-coded at the 99th percentile within yearly age bins for each calendar month. The scatter plot shows covariate-adjusted means by age in quarters, and the lines show a linear regression fit in months on both sides of the eligibility threshold. The sample consists of work-registered individuals on SNAP in September 2013 and in the subset of counties where work requirements remain on after October 2013. Panel (b) replicates the same analysis among those participating in September 2011, when the ARRA exemption that suspended work requirements was in effect for an additional two years. 
Table 5: RD Estimates of Key Outcomes, 18 Months After Work Requirements

\begin{tabular}{|c|c|c|}
\hline & $\begin{array}{c}\text { Main Stock } \\
\text { (September 2013) }\end{array}$ & $\begin{array}{c}\text { Placebo Stock } \\
\text { (ARRA Period) }\end{array}$ \\
\hline \multicolumn{3}{|c|}{ Panel A. SNAP Participation } \\
\hline \multirow[t]{2}{*}{ Discontinuity } & -0.234 & -0.001 \\
\hline & $(0.015)$ & $(0.020)$ \\
\hline Control Mean & 0.632 & 0.669 \\
\hline$N$ & 15,692 & 13,097 \\
\hline \multicolumn{3}{|c|}{ Panel B. Employment } \\
\hline \multirow[t]{2}{*}{ Discontinuity } & 0.010 & 0.007 \\
\hline & $(0.013)$ & $(0.012)$ \\
\hline Control Mean & 0.273 & 0.277 \\
\hline$N$ & 16,840 & 20,233 \\
\hline \multicolumn{3}{|c|}{ Panel C. Employed or Earned Income } \\
\hline \multirow[t]{2}{*}{ Discontinuity } & -0.004 & 0.009 \\
\hline & $(0.014)$ & $(0.014)$ \\
\hline Control Mean & 0.348 & 0.333 \\
\hline$N$ & 18,859 & 19,140 \\
\hline \multicolumn{3}{|c|}{ Panel D. Earnings } \\
\hline \multirow[t]{2}{*}{ Discontinuity } & -12.2 & 39.8 \\
\hline & $(20.7)$ & $(27.2)$ \\
\hline Control Mean & 365.2 & 347.7 \\
\hline$N$ & 15,930 & 15,701 \\
\hline \multicolumn{3}{|c|}{ Panel E. Log Earnings } \\
\hline \multirow[t]{2}{*}{ Discontinuity } & -0.012 & 0.078 \\
\hline & $(0.080)$ & $(0.083)$ \\
\hline Control Mean & 1.935 & 1.876 \\
\hline$N$ & 19,729 & 19,955 \\
\hline \multicolumn{3}{|c|}{ Panel F. Exemption (Other than Age) } \\
\hline \multirow[t]{2}{*}{ Discontinuity } & 0.056 & -0.020 \\
\hline & $(0.013)$ & $(0.011)$ \\
\hline Control Mean & 0.095 & 0.115 \\
\hline$N$ & 16,379 & 17,893 \\
\hline
\end{tabular}

Notes: Table shows regressions coefficients from local linear RD specifications with a uniform kernel, corresponding to RD figures in the text. Standard errors clustered by monthly age (the running variable) are reported in parentheses. Control mean is the predicted mean of the corresponding outcome variable immediately to the right of the age 50 threshold (the intercept with the cutoff). Employment and earnings are measured from UI records. Log earnings calculated as $\ln (y+1)$. Earnings include those with zero UI earnings, and are winsorized at the 99 percent level by yearly age within each calendar month. The variables Earned Income and Exemption status are reported on DSS records. 
are, however, consistent with emerging evidence that populations with low to no earnings do not respond to shocks in unearned income. For example, despite her estimate of large intensive-margin responses, Deshpande (2016) finds no corresponding employment response to SSI income despite the income losses being over $\$ 600$ per month. We turn next to an examination of whether our average null results hold across the entire sample.

\section{$5.2 \quad$ Heterogeneity of Labor Market Effects}

The RD regressions in Section 5.1 fail to detect a statistically significant impact of work requirements on labor market outcomes on average. This null result may mask a positive effect for a small subgroup of participants. Work requirements may induce no change in earnings among the majority of participants who are far from the threshold - either because they are so far below it that meeting it would be too difficult or because they would be above it even in the absence of work requirements - while inducing a substantial change in earnings among individuals near the cutoff.

We therefore examine the heterogeneity of the effect of work requirements on earnings. We estimate unconditional quantile regressions using the recentered influence function method (Firpo et al. 2009). For the qth quantile of the overall monthly earnings distribution, $y_{q}$, we compute that quantile in each age bin and estimate a donut RD of how that quantile changes at the age 50 cutoff. The regression specification excludes controls other than age and otherwise mirrors our baseline donut RD specification (Equation 2). The coefficient on the indicator for below age 50 in the $q$ th regression can be interpreted as the effect of work requirements on earnings at $y_{q}$, the $q$ th percentile of the unconditional monthly earnings distribution. By estimating the unconditional quantile effect at each percentile, we trace out the potentially heterogeneous effect along the earnings distribution. Because these unconditional quantile regressions compute the unconditional (marginal) effects across the underlying distribution of observables, they recover average impacts without needing to hold other covariates (such as age) constant. We discuss identification for the unconditional quantile regressions in Appendix D.5.

Figure 7 plots the main coefficients of interest at each percentile using the stock population, and the shaded region shows 95 percent confidence intervals. Since the RD estimate of the effect in the lower range of the distribution is mechanically zero, we only report results for the 60 th percentile and above. ${ }^{21}$ The vertical red line is placed at the minimum earnings required to maintain eligibility through working, calculated as 80 times the hourly minimum wage over the period ( $\$ 7.25$ per hour).

\footnotetext{
${ }^{21}$ The bottom two-thirds of the earnings distribution on both sides of the age 50 cutoff have zero earnings.
} 
Figure 7: Heterogeneity in RD Estimates of Earnings

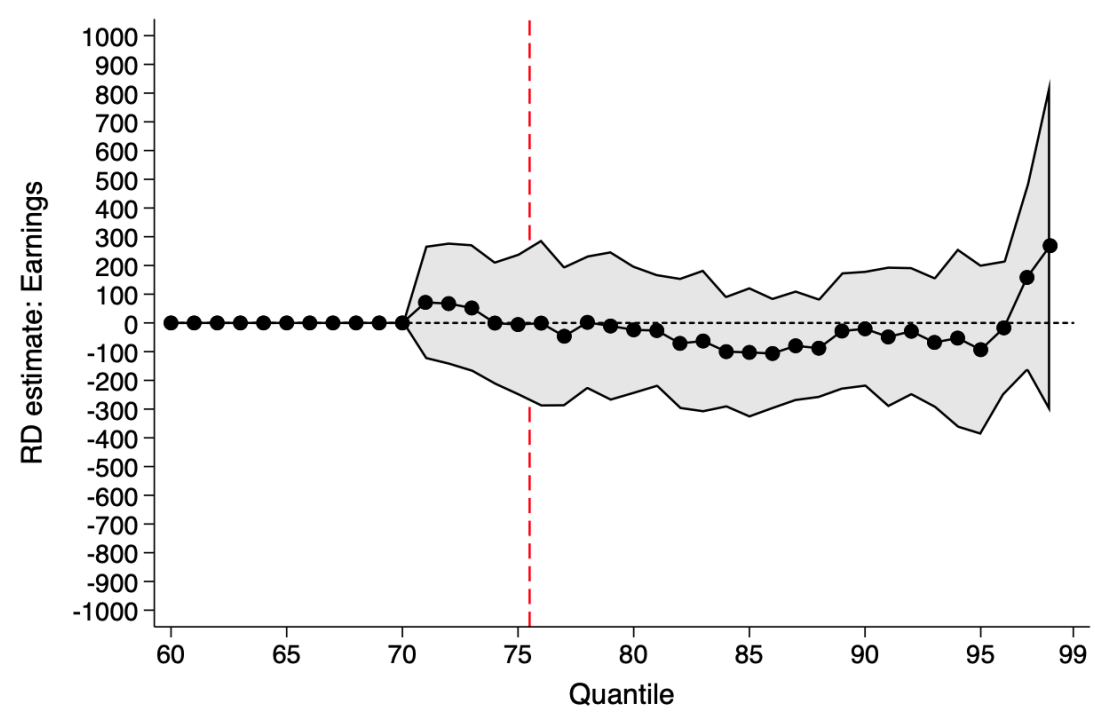

(a) 18 Months After Work Requirements

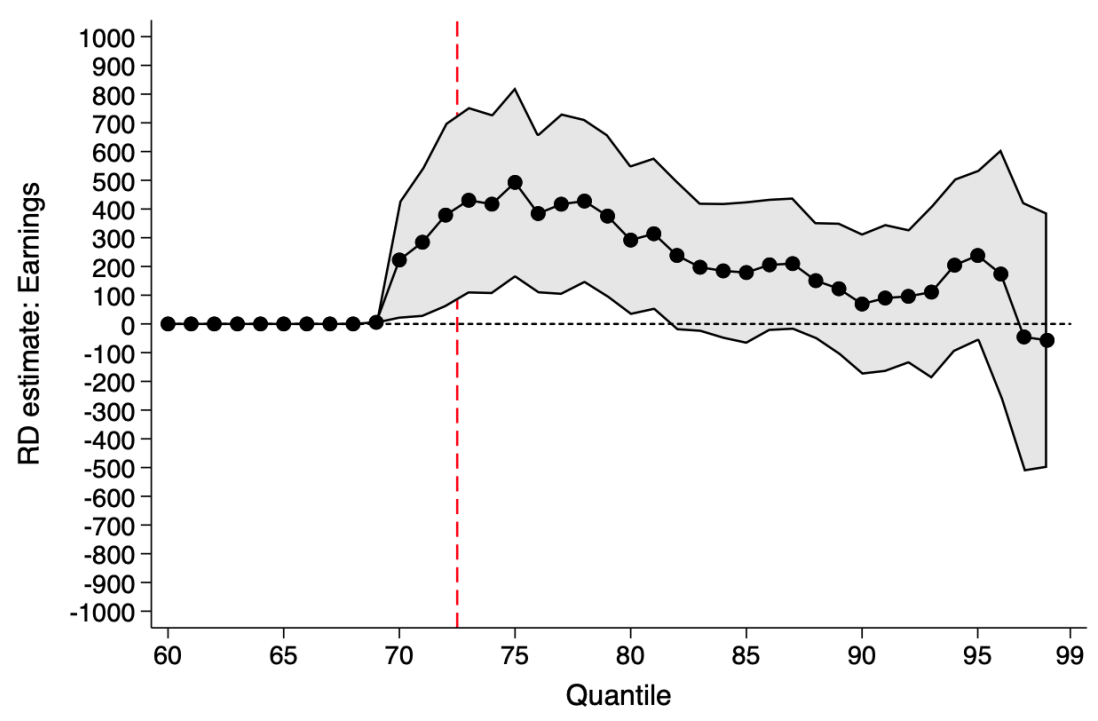

(b) 24 Months After Work Requirements

Notes: Figure plots coefficients from individual-level regressions of monthly earnings. Each coefficient is from a separate regression for that quantile using the recentered influence function method of Firpo et al. (2009). Top panel measures earnings in March 2015; bottom panel measures earnings in September 2015. Shading denotes 95 percent confidence intervals. For visual clarity, we omit presenting the 99th percentile because the point estimate at 18 months is very imprecise, making it difficult to discern the magnitudes of the other estimates. 
Figure 7a shows the estimates 18 months after the start of work requirements; Figure 7b shows them at 24 months. At 18 months, just after the completion of the gradual roll-out of work requirements, the estimated earnings effects are not statistically distinguishable from zero across the entire earnings distribution. This result is consistent with the estimated null average effects of work requirements on employment and earnings in Figures 5a and 6a. ${ }^{22}$ An additional six months after the completion of the roll-out, however, the estimates are consistently positive and statistically significant between the 69th and 81st percentiles of the earnings distribution, inclusive (Figure $7 \mathrm{~b}$ ). The peak of the point estimates is at the 75th percentile, slightly above the minimum threshold for meeting work requirements. The estimates at the top and bottom ends of the earnings distribution are statistical zeros. With the caveats concerning interpretation of quantile regressions described in Appendix D.5, this pattern is consistent with a positive response among SNAP participants who are already near the work requirements threshold. The increases are primarily in the range of $\$ 275$ to $\$ 500$ per month, which is equivalent to shifting a portion of the earnings distribution to the right by three to seven percentiles in the vicinity of the minimum work requirements threshold. This is a substantial increase in earnings: the federal poverty line for a single-person household in 2015 was $\$ 981$ per month.

The pattern documented in Figure $7 \mathrm{~b}$ would imply that work requirements have a meaningful positive earnings impact in a narrow subset of the earnings distribution of SNAP participants. However, the zeros estimated just six months earlier in Figure 7a dictate caution in the interpretation of these results. Because our primary dataset ends in December 2015, we cannot check whether the positive effects documented in September 2015 (Figure 7b) persist. We discuss possible explanations for a delayed response in Appendix D.5, including labor market improvements in mid-2015 and features of SNAP that make work requirements effectively more stringent over time.

A natural question is whether the earnings increases in Figure 7b, if real, are concentrated among participants who exit SNAP and work more to compensate for the loss of benefits or among those who work more to retain SNAP eligibility. Unfortunately, our RD identification strategy will not yield causal estimates for these mechanisms; examining earnings for those remaining on SNAP in September 2015, for example, involves conditioning on the (endogenous) outcome of not having exited within 24 months of work requirements. We attempt to disentangle the mechanisms in Appendix D.6 using machine learning techniques. Unfortunately, the results are inconclusive (see Appendix Table D.3).

\footnotetext{
${ }^{22}$ Appendix Figure C.14 considers the analogous exercise for the placebo cohorts (on SNAP in September 2011). We estimate zeros along the entire earnings distribution in the placebo period at both the 18-month and 24-month intervals.
} 
We therefore conclude that work requirements may appreciably increase earnings along a narrow range of the earnings distribution, but the primary mechanism for that possible earnings increase remains uncertain.

\subsection{Welfare Impacts}

The previous results establish that work requirements dramatically reduce overall participation and retention among the stock population of beneficiaries while possibly increasing earnings among a subset of this population. A social planner setting rules for SNAP eligibility would trade off these competing forces. While a full accounting of the welfare impacts of work requirements is outside the scope of this paper, this section presents a stylized calculation of the marginal value of public funds (MVPF) of work requirements in SNAP as a starting point.

The MVPF is the ratio of a program's beneficiaries' willingness to pay for the program to the government's cost of providing it (Hendren 2016). In keeping with the literature, we report the MVPF of an expansion, rather than a contraction, in government spending. We therefore calculate the MVPF for the elimination of work requirements. The MVPF is given by:

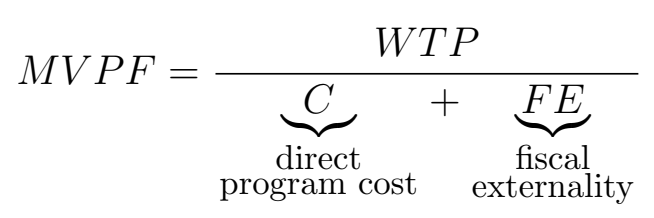

where the numerator represents the relevant ABAWDs' willingness to pay out of their own income to eliminate work requirements, and the denominator represents the total cost to the government of eliminating work requirements. The total cost is the sum of the direct cost of providing benefits to additional ABAWDs who participate in SNAP only in the absence of work requirements (the induced exiters of Appendix D.6), and fiscal externalities such as reductions in income tax revenue. The relevant population for both the numerator and the denominator is the set of ABAWDs who would participate in SNAP in the absence of work requirements.

If the MVPF is larger than the MVPFs of other programs targeting the same population, then eliminating SNAP work requirements would transfer more resources to SNAP participants per dollar of public expenditure than those other programs. Our calculations suggest that the elimination of SNAP work requirements likely has an MVPF between 0.86 and 1.35. The upper bound of the MVPF assumes that individuals pay a 
utility cost for the large behavior change of working more, whereas the lower bound assumes envelope theorem arguments apply. Appendix D.7 reports the details of the calculations.

Most existing estimates of the MVPF of various aspects of SNAP, and cash transfer programs more broadly, are near one. Hendren and Sprung-Keyser (2020) provide MVPFs for a range of programs based on prior literature that can serve as benchmarks: the MVPFs for other aspects of SNAP range from 0.42 to 1.04, with most estimates close to 1; the MVPFs for housing vouchers are between 0.65 and 0.76; the MVPFs for the 1986 and 1993 Earned Income Tax Credit (EITC) expansions are between 1.0 and 1.20; and the MVPFs for other cash transfer programs are between 0.81 and 0.87 . Under the assumption that the earnings response to SNAP work requirements, if any, has a non-marginal utility cost, the MVPF of eliminating work requirements compares favorably with other policies targeting the SNAP population.

Of course, these stylized calculations omit potentially sizable fiscal externalities arising from the elimination of work requirements. In the calculation, we only consider the portion that we can estimate: the income tax revenue change from the direct response to work requirements. However, the literature has documented additional effects from expanding SNAP participation, which may produce other fiscal externalities. SNAP benefits improve nutrition and have been shown to reduce health care spending, much of which is subsidized by the government through the tax treatment of employer-based health insurance or, more directly, through Medicaid (Sonik 2016, East and Friedson 2020). SNAP benefits also decrease crime (Tuttle 2019), which may reduce direct costs to victims and government spending on the criminal justice system. Each of these potential externalities would decrease the magnitude of the denominator in the MVPF calculation, increasing the MVPF. A possible countervailing externality would exist if there are long-term positive labor market effects of work requirements that are not detectable in our sample. The closest available evidence comes from Card and Hyslop (2005), who document no difference in long-run earnings from a Canadian welfare program. On net, the evidence from the literature indicates that any omitted fiscal externalities are likely to increase the MVPF we calculated above, rather than decrease it.

\section{Conclusion}

As work requirements in means-tested programs come to the forefront of modern policy debates, it is critical to understand their causal impact on program participation and work. On one hand, work requirements may reduce benefits for economically vulnerable adults 
without a counterbalancing improvement in labor market outcomes. On the other hand, work requirements could successfully incentivize labor force participation, thereby helping to counter means-tested programs' disincentives to work.

We measure the magnitude of both phenomena by combining SNAP and UI administrative data from Virginia with quasi-experimental policy variation. We find that SNAP work requirements dramatically reduce participation among affected adults, with point estimates suggesting a 53 percent decline in participation by the completion of the roll-out. Focusing on the sample of people already on SNAP just before the reintroduction of work requirements, we estimate a 37 percent drop in retention. These declines are largest among beneficiaries who, prior to the reinstatement of work requirements, are homeless or have no earned income. At the same time, we statistically rule out a large average increase in UI-covered employment, and fail to detect an increase in self-employment or wage earnings along a large majority of the distribution. We find tentative evidence of increased earnings in the vicinity of the eligibility threshold. In practice, work requirements appear to screen out a large number of potential SNAP beneficiaries in exchange for a possible earnings increase among a limited subset of individuals. The similarity of participation patterns at younger ages subject to work requirements suggests that our results may also generalize to SNAP beneficiaries who are substantially younger than 50 (Figure 2b).

Given our large documented impacts on program exit, it is notable that we find no corresponding evidence of substantial labor market responses. This lack of response may indicate that SNAP benefits are not binding disincentives against labor force participation for a population that overwhelmingly has no income, whether earned or unearned. If that is the case, then work requirements aimed at countering the disincentives of benefits will not be effective as they do not address more pressing underlying barriers to work. Future research could identify such barriers, and assess whether removing them would increase self-sufficiency, especially among those who do not earn any income. 


\section{References}

Abadie, Alberto, Matthew M. Chingos, and Martin R. West, "Endogenous Stratification in Randomized Experiments," NBER Working Paper No. w19742, 2013.

Angrist, Joshua and Jorn-Steffen Pischke, Mostly Harmless Econometrics: An Empiricist's Companion, Princeton University Press, 2009.

Autor, David H. and Mark G. Duggan, "Distinguishing Income from Substitution Effects in Disability Insurance," American Economic Review: Papers 83 Proceedings, 2007, $97(2), 119-123$.

Bee, Charles Adam and Joshua Mitchell, "Do Older Americans Have More Income Than We Think?," 2017.

Belloni, Alexandre, Daniel Chen, Victor Chernozhukov, and Christian Hansen, "Sparse Models and Methods for Optimal Instruments With an Application to Eminent Domain," Econometrica, 2012, 80 (6), 2369-2429.

Besley, Timothy and Stephen Coate, "Workfare versus Welfare: Incentive Arguments for Work Requirements in Poverty-Alleviation Programs," American Economic Review, 1992, 82 (1), 249-261.

Bitler, Marianne, Jonah Gelbach, and Hillary Hoynes, "What Mean Impacts Miss: Distributional Effects of Welfare Reform Experiments," American Economic Review, 2006, $96(4), 988-1012$.

Calonico, Sebastian, Matias D. Cattaneo, and Rocio Titiunik, "Robust Nonparametric Confidence Intervals for Regression-Discontinuity Designs," Econometrica, 2014, 82 (6), 2295-2326.

Card, David and Dean R Hyslop, "Estimating the Effects of a Time-Limited Earnings Subsidy for Welfare-Leavers," Econometrica, 2005, 73 (6), 1723-1770.

_, David S Lee, Zhuan Pei, and Andrea Weber, "Regression Kink Design: Theory and Practice," NBER Working Paper w22781, National Bureau of Economic Research, Cambridge, MA 2016.

Cattaneo, Matias D., Michael Jansson, and Xinwei Ma, "Manipulation Testing Based on Density Discontinuity," The Stata Journal: Promoting communications on statistics and Stata, 2018, 18 (1), 234-261.

Cesarini, David, Erik Lindqvist, Matthew J Notowidigdo, and Robert Östling, "The effect of wealth on individual and household labor supply: evidence from Swedish lotteries," American Economic Review, 2017, 107 (12), 3917-46.

Chan, Marc K., "A Dynamic Model of Welfare Reform," Econometrica, 2013, 81 (3), 941-1001. 
- and Robert Moffitt, "Welfare Reform and the Labor Market," Annual Review of Economics, 2018, 10 (1), 347-381.

Chen, Susan and Wilbert van der Klaauw, "The Work Disincentive Effects of the Disability Insurance Program in the 1990s," Journal of Econometrics, 2008, 142 (2), 757784.

Cuffey, Joel, Elton Mykerezi, and Timothy Beatty, "Food Assistance and Labor Force Outcomes of Childless Adults: Evidence from the CPS," Working Paper, 2015.

Danielson, Caroline and Jacob Alex Klerman, "Why Did the Food Stamp Caseload Decline (and Rise)? Effects of Policies on the Economy," Santa Monica, CA: RAND Corporation, 2006.

Dean, David, John Pepper, Robert Schmidt, and Steven Stern, "The Effect of Vocation Rehabilitation Services for People with Mental Illness," Journal of Human Resources, 2017, 52 (3), 826-858.

Delgado, Jason, "DCF rolls back food stamp work search requirements," Jul 2020.

Deshpande, Manasi, "The Effect of Disability Payments on Household Earnings and Income: Evidence from the SSI Children's Program," The Review of Economics and Statistics, 2016, 98 (4), 638-654.

- and Yue Li, "Who Is Screened Out? Application Costs and the Targeting of Disability Programs," American Economic Journal: Economic Policy, 2019, (forthcoming).

_ , Tal Gross, and Yalun Su, "Disability and Distress: The Effect of Disability Programs on Financial Outcomes," 2019.

East, Chloe and Andrew Friedson, "An Apple a Day? Adult Food Stamp Eligibility and Health Care Utilization," American Journal of Health Economics, 2020, (forthcoming).

Fadulu, Lola, "Why States Want Certain Americans to Work for Medicaid," The Atlantic, 2019.

Fang, Hanming and Michael Keane, "Assessing the Impact of Welfare Reform on Single Mothers," Brookings Papers on Economic Activity, 2004, pp. 1-116.

Fetter, Daniel K. and Lee M. Lockwood, "Government Old-Age Cupport and Labor Supply: Evidence from the Old Age Assistance Program," American Economic Review, 2018, 108 (8), 2174-2211.

Finkelstein, Amy and Matthew J Notowidigdo, "Take-up and Targeting: Experimental Evidence from SNAP," The Quarterly Journal of Economics, 2019, (April).

Firpo, Sergio, Nicole M Fortin, and Thomas Lemieux, "Unconditional quantile regressions," Econometrica, 2009, 77 (3), 953-973.

Fraker, Thomas and Robert Moffitt, "The effect of food stamps on labor supply: A bivariate selection model," Journal of Public Economics, 1988, 35 (1), 25 - 56. 
Frandsen, Brigham R., "Party Bias in Union Representation Elections: Testing for Manipulation in the Regression Discontinuity Design when the Running Variable is Discrete," Advances in Econometrics, 2017, 38, 281-315.

Ganong, Peter and Jeffrey B. Liebman, "The Decline, Rebound, and Further Rise in SNAP Enrollment: Disentangling Business Cycle Fluctuations and Policy Changes," American Economic Journal: Economic Policy, November 2018, 10 (4), 153-76.

Gelber, Alexander, Timothy J Moore, and Alexander Strand, "The effect of disability insurance payments on beneficiaries' earnings," American Economic Journal: Economic Policy, 2017, 9 (3), 229-61.

Gelman, Andrew and Guido Imbens, "Why High-order Polynomials Should Not Be Used in Regression Discontinuity Designs," Journal of Business 83 Economic Statistics, 2017, 0 (0), 0-0.

Gray, Colin, "Leaving Benefits on the Table : Evidence from SNAP," Journal of Public Economics, 2019, 179.

Greenberg, David, Victoria Deitch, and Gayle Hamilton, "Welfare-to-Work Program: Benefits and Costs," Technical Report February 2009.

Grogger, Jeffrey and Lynn A. Karoly, "Welfare Reform: Effects of a Decade of Change," Harvard University Press, 2005.

Hagstrom, Paul A., "The Food Stamp Participation and Labor Supply of Married Couples: An Empirical Analysis of Joint Decisions," The Journal of Human Resources, 1996, 31 (2), 383-403.

Hahn, Heather and Ron Haskins, "Federal Work Requirements Debate," Poverty and Social Policy Debate Series, American Enterprise Institute 2018.

Han, Jeehoon, "The Impact of SNAP Work Requirements on Labor Supply," 2020.

Harris, Timothy F., "Do SNAP Work Requirements Work?," Economic Inquiry, 2021, 59 (1), 72-94.

Hastings, Justine S. and Jesse M. Shapiro, "How are SNAP Benefits Spent? Evidence from a Retail Panel," American Economic Review, 2018, 108 (12), 3493-3540.

Hendren, Nathaniel, "The policy elasticity," Tax Policy and the Economy, 2016, 30 (1), 51-89.

- and Ben Sprung-Keyser, "A Unified Welfare Analysis of Government Policies," Quarterly Journal of Economics, 2020, 135 (3), 1209-1318.

Homonoff, Tatiana and Jason Somerville, "Program Recertification Costs: Evidence from SNAP," 2019, pp. 1-43.

Hoynes, Hilary and Diane Whitmore Schanzenbach, "Work incentives and the Food Stamp Program," Journal of Public Economics, 2012, 96 (1), 151 - 162. 
Hoynes, Hilary W and Diane Whitmore Schanzenbach, "Consumption responses to in-kind transfers: Evidence from the introduction of the food stamp program," American Economic Journal: Applied Economics, 2009, 1 (4), 109-39.

_ , Leslie McGranahan, and Diane W Schanzenbach, "SNAP and food consumption," SNAP Matters: How Food Stamps Affect Health and Well Being, 2015, pp. 107-133.

Imbens, Guido W, Donald B Rubin, and Bruce I Sacerdote, "Estimating the effect of unearned income on labor earnings, savings, and consumption: Evidence from a survey of lottery players," American Economic Review, 2001, 91 (4), 778-794.

Keane, Michael and Robert Moffitt, "A Structural Model of Multiple Welfare Program Participation and Labor Supply," International Economic Review, 1998, 39 (3), 553-589.

McClelland, Robert and Shannon Mok, "A review of recent research on labor supply elasticities," Technical Report, Congressional Budget Office 2012.

McCrary, Justin, "Manipulation of the Running Variable in the Regression Discontinuity Design: A Density Test," Journal of Econometrics, 2008, 142 (2), 698-714.

Meyer, Bruce D and Nikolas Mittag, "Using Linked Survey and Administrative Data To Better Measure Income," American Economic Journal: Applied Economics, 2019, 11 (2), 176-204.

Meyer, Bruce D., Robert M Goerge, and Nikolas Mittag, "Errors in Survey Reporting and Imputation and their Effects on Estimates of Food Stamp Program Participation," 2014.

Nichols, Albert L. and Richard J. Zeckhauser, "Targeting Transfers through Restrictions on Recipients," American Economic Review, 1982 , 72 (2), 372-377.

of Labor Statistics, Bureau, "Local Area Unemployment Statistics: Unemployment Rates for States, 2015 Annual Averages," 2016.

on Budget, Center and Policy Priorities, "States Have Requested Waivers from SNAP's Time Limit in High Unemployment Areas for the Past Two Decades," Dec 2019.

Peterson, Kristina, "Republicans Are Open to Possible Food-Stamps Deal With Democrats," Jul 2020.

Rachidi, Angela and Robert Doar, "How Effective Are Work Requirements?," AEI article, American Enterprise Institute 2018.

Ribar, David C., Marilyn Edelhoch, and Qiduan Liu, "Food Stamp Participation among Adult-Only Households," Southern Economic Journal, 2010, 77 (2), 244-270.

Ritter, Joseph A., "Incentive effects of SNAP work requirements," December 2018.

Sonik, Rajan, "Massachusetts Inpatient Medicaid Cost Response to Increased Supplemental Nutrition Assistance Program Benefits," American Journal of Public Health, 2016,106 (3), 443-448. 
Stacy, Brian, Erik Scherpf, and Young Jo, "The Impact of SNAP Work Requirements," Working Paper, 2018.

Tuttle, Cody, "Snapping Back: Food Stamp Bans and Criminal Recidivism," American Economic Journal: Economic Policy, May 2019, 11 (2), 301-27.

USDA Food and Nutrition Service, "SNAP Work Requirements," May 2019.

_ , "FY 2015 Allocation of 15 percent Exemptions - Total, Including Carryover," May 2020.

Wilde, Parke E., Peggy Cook, Craig Gundersen, Mark Nord, and Laura Tiehen,

"The Decline In Food Stamp Program Participation In The 1990's," Food Assistance and Nutrition Research Reports, 2000.

Ziliak, James P., "Income, program participation, poverty, and financial vulnerability: Research and data needs," Journal of Economic and Social Measurement, 2015, 40 (1-4), $27-68$.

_, Craig Gundersen, and David N. Figlio, "Food Stamp Caseloads over the Business Cycle," Southern Economic Journal, April 2003, 69 (4), 903-919. 